University of Wollongong

Research Online

Faculty of Engineering and Information

Faculty of Engineering and Information

Sciences - Papers: Part B

Sciences

2017

Effects of aerodynamic damping on the tower load of offshore horizontal axis wind turbines

Xiong Liu

University of Wollongong, Shantou University, xiong@uow.edu.au

Cheng Lu

University of Wollongong, chenglu@uow.edu.au

Gangqiang Li

CRRC Shandong Co. Ltd.

Ajit R. Godbole

University of Wollongong, agodbole@uow.edu.au

Yan Chen

Shantou University

Follow this and additional works at: https://ro.uow.edu.au/eispapers1

Part of the Engineering Commons, and the Science and Technology Studies Commons

Research Online is the open access institutional repository for the University of Wollongong. For further information contact the UOW Library: research-pubs@uow.edu.au 


\title{
Effects of aerodynamic damping on the tower load of offshore horizontal axis wind turbines
}

\author{
Abstract \\ Aerodynamic damping has an important effect on the dynamic response of offshore Horizontal Axis Wind \\ Turbines (HAWTs). In this paper, an analysis of the loads on offshore HAWTs is presented. The analysis \\ combines the aerodynamics, hydrodynamics and structural dynamics of the structure, and includes the \\ effects of aerodynamic damping. The aim is to better understand the role of aerodynamic damping during \\ the interaction of wind and wave and the structure, and to quantitatively evaluate the effects of \\ aerodynamic damping on the lifetime fatigue load on offshore HAWT towers. The aerodynamic loads are \\ estimated using the Blade Element-Momentum (BEM) theory, including the effects of dynamic inflow and \\ dynamic stall. The wave dynamics is estimated assuming 'random sea state' described by the JONSWAP \\ spectrum, with wave loads calculated using Morison's equation and water kinematics modelled using \\ linear wave theory. Two aerodynamic damping models are proposed: (1) a model based on the analysis of \\ the rotor aerodynamics incorporating the tower-top motion of a constant-speed wind turbine, which is \\ then modified for variable-speed wind turbines by introducing a correction factor; and (2) a model based \\ on Salzmann and van der Tempel's method (Salzmann and van der Tempel, 2005) to calculate the \\ aerodynamic damping as the increase in the thrust per unit increase in the wind speed. The models are \\ incorporated into a transient load analysis. The effects of aerodynamic damping on the lifetime fatigue \\ loads of the tower are then investigated through load analysis of a $5 \mathrm{MW}$ offshore HAWT. In addition, the \\ influence of different aerodynamic damping calculation methods on the prediction of fatigue loads is \\ studied. \\ Disciplines \\ Engineering | Science and Technology Studies

\section{Publication Details} \\ Liu, X., Lu, C., Li, G., Godbole, A. \& Chen, Y. (2017). Effects of aerodynamic damping on the tower load of \\ offshore horizontal axis wind turbines. Applied Energy, 204 1101-1114.
}




\title{
Effects of aerodynamic damping on the tower load of offshore
}

\author{
horizontal axis wind turbines ${ }^{1}$
}

\author{
Xiong Liu ${ }^{\mathrm{a}, \mathrm{b}}$, Cheng Lu ${ }^{\mathrm{a}, *}$, Gangqiang Lic ${ }^{\mathrm{c}}$, Ajit Godbole ${ }^{\mathrm{a}}$, Yan Chen ${ }^{\mathrm{b}}$ \\ a School of Mechanical, Materials and Mechatronic Engineering, University of Wollongong, NSW 2522, \\ Australia \\ ${ }^{\mathrm{b}}$ College of Engineering, Shantou University, Shantou 515063, China \\ ${ }^{\mathrm{c}}$ CRRC Shandong Co. Ltd., Jinan 250022, China
}

\begin{abstract}
Aerodynamic damping has an important effect on the dynamic response of offshore Horizontal Axis Wind Turbines (HAWTs). In this paper, an analysis of the loads on offshore HAWTs is presented. The analysis combines the aerodynamics, hydrodynamics and structural dynamics of the structure, and includes the effects of aerodynamic damping. The aim is to better understand the role of aerodynamic damping during the interaction of wind and wave and the structure, and to quantitatively evaluate the effects of aerodynamic damping on the lifetime fatigue load on offshore HAWT towers. The aerodynamic loads are estimated using the Blade ElementMomentum (BEM) theory, including the effects of dynamic inflow and dynamic stall. The wave dynamics is estimated assuming 'random sea state' described by the JONSWAP spectrum, with wave loads calculated using Morison's equation and water kinematics modelled using linear wave theory. Two aerodynamic damping models are proposed: (1) a model based on the analysis of the rotor aerodynamics incorporating the tower-top motion of a constant-speed wind turbine, which is then modified for variable-speed wind turbines by introducing a correction factor; and (2) a model based on Salzmann and van der Tempel's method [1] to calculate the aerodynamic damping as the increase in the thrust per unit increase in the wind speed. The models are incorporated into a transient load analysis. The effects of aerodynamic damping on the lifetime fatigue loads of
\end{abstract}

\footnotetext{
${ }^{1}$ A short version of the paper was presented at ICAE2016 on Oct 8-11, Beijing, China. This paper is a substantial extension of the conference paper.
} 
the tower are then investigated through load analysis of a $5 \mathrm{MW}$ offshore HAWT. In addition, the influence of different aerodynamic damping calculation methods on the prediction of fatigue loads is studied.

Keywords: Wind energy; Offshore wind turbine; Aerodynamic damping; Wave load; Fatigue load

* Corresponding author. Tel.: +61-2-4221-4639; Fax: +61-2-4221-5474.

E-mail address: chenglu@uow.edu.au (C. Lu).

\begin{tabular}{|c|c|c|c|}
\hline \multicolumn{4}{|c|}{ Nomenclature } \\
\hline \multirow{5}{*}{$\begin{array}{l}a \\
a^{\prime} \\
A_{w} \\
b\end{array}$} & \multirow{2}{*}{$\begin{array}{l}\text { axial flow induction factor, dimensionless } \\
\text { tangential flow induction factor, dimensionless }\end{array}$} & \multirow{2}{*}{$\begin{array}{l}M_{a} \\
M_{n}\end{array}$} & Mach number, dimensionless \\
\hline & & & $n^{\text {th }}$ modal mass $(\mathrm{kg})$ \\
\hline & wave amplitude (m) & $m$ & mass $(\mathrm{kg})$ \\
\hline & aerodynamic damping correction factor. & $\mathbf{P}$ & load matrix \\
\hline & dimensionless & $Q$ & torque $(\mathrm{N} \mathrm{m})$ \\
\hline$B$ & the number of blades dimensionless & $r$ & radius of blade section on blade $(\mathrm{m})$ \\
\hline$c$ & chord lenoth $(\mathrm{m})$ & $R$ & rotor radius $(\mathrm{m})$ \\
\hline$c_{0}$ & aerodvnamic damping $\left(\mathrm{N} \mathrm{s} \mathrm{m}^{-1}\right)$ & $t$ & time $(\mathrm{s})$ \\
\hline $\mathbf{C}$ & damping matrix & $T$ & axial force $(\mathrm{N})$ \\
\hline$C_{C}$ & chord wise force coefficient, dimensionless & $T_{p}$ & peak wave period (s) \\
\hline$C_{D}$ & drag coefficient dimensionless & $U$ & wind velocity $\left(\mathrm{m} \mathrm{s}^{-1}\right)$ \\
\hline$C_{I}$ & lift coefficient, dimensionless & $U_{w}$ & wave induced velocity $\left(\mathrm{m} \mathrm{s}^{-1}\right) W$ \\
\hline$C_{M}$ & hydrodynamic inertia coefficient, & airf & velocity $\left(\mathrm{m} \mathrm{s}^{-1}\right)$ \\
\hline & dimensionless & $z$ & depth below water surface (m) \\
\hline$C_{N}$ & normal force coefficient, dimensionless & & \\
\hline$d$ & water depth (m) & Gre & etters \\
\hline$D$ & drag force $(\mathrm{N})$ & $\alpha$ & angle of attack (rad) \\
\hline$D_{t}$ & diameter of tower section $(\mathrm{m})$ & $\beta$ & airfoil twist angle (rad) \\
\hline$f$ & wave frequency $(\mathrm{Hz})$ & $\rho$ & density $\left(\mathrm{kg} \mathrm{m}^{-3}\right)$ \\
\hline$f_{p}$ & peak wave frequency $(\mathrm{Hz})$ & $\Omega$ & rotor angular velocity $\left(\mathrm{rad} \mathrm{s}^{-1}\right)$ \\
\hline$F$ & force $(\mathrm{N})$ & $\phi$ & inflow angle (rad) \\
\hline$g$ & gravitational acceleration $\left(\mathrm{m} \mathrm{s}^{-2}\right)$ & $\theta$ & rotor azimuth angle (rad) \\
\hline$h$ & height above sea level (m) & $\chi$ & shaft tilt angle (rad) \\
\hline$H_{s}$ & significant wave height (m) & $\beta_{0}$ & rotor cone angle (rad) \\
\hline$k$ & wave number, dimensionless & $\omega$ & angular frequency $\left(\mathrm{rad} \mathrm{s}^{-1}\right)$ \\
\hline $\mathbf{K}$ & stiffness matrix & $\gamma$ & JONSWAP peak-shape parameter, \\
\hline$L$ & lift force $(\mathrm{N})$ & & dimensionless \\
\hline $\mathbf{M}$ & mass matrix & $\xi$ & modal aerodynamic damping ratio, \\
\hline$M$ & moment $(\mathrm{N} \mathrm{m})$ & & dimensionless \\
\hline
\end{tabular}




\section{Introduction}

The use of renewable energy sources has attracted increasing interest over the past decades due to the quest for a low-carbon economy and an increasing awareness of the need for sustainable development [2, 3]. Among the various renewable energy alternatives, wind energy is considered to be the most cost-effective, and has seen the fastest growth due to a significant reduction in its operating cost [4-7]. At the end of 2015, wind power reached a global capacity of $433 \mathrm{GW}$ and for the previous 5 years increased in installed capacity by $12-19 \%$ per annum [8]. The wind energy market is still growing rapidly and it is expected that by 2020 the global capacity will increase to $792 \mathrm{GW}[8]$.

To date, wind farms are mostly deployed onshore due to the relatively lower cost of construction, operation and maintenance. However, offshore locations generally have higher, more consistent wind speeds, less turbulence and lower wind shear, so that offshore wind farms can offer more, better quality renewable energy than their onshore counterparts $[3,9,10]$. Also, in some countries the best onshore locations are no longer available, and there is considerable public opposition to a significant increase in onshore wind power installations. In reality, the development of offshore Horizontal Axis Wind Turbines (HAWTs) has never lost the attention of the energy industry. Over the last decade, offshore wind power capacity increased considerably and reached $12.1 \mathrm{GW}$ at the end of 2015, approximately $2.8 \%$ of the global installed wind power capacity. Although the advantages of offshore projects are counter-balanced by the higher demand on materials, manufacturing, transportation, construction and maintenance, more and more research is being directed to make the deployment of offshore wind turbines more cost-effective. A substantial growth of offshore wind power installation in the future can offer a possible solution to the problem of providing for future green energy needs $[10,11]$.

Although offshore wind resources are of better quality and more abundant, the more severe environment demands additional design considerations for offshore wind turbines to ensure safe operation. Firstly, larger offshore wind turbines are being considered to enable greater wind energy capture at lower cost. The proposed increase in size introduces significant aeroelastic effects, which are caused by the interaction of aerodynamic loads, elastic deflections and inertial dynamics [12-14]. Another important problem is the combined effect of 
wind and wave loads on the structure. The coincidence of structural resonance with aerodynamic and hydrodynamic forces on the wind turbine may result in large-amplitude vibrations with the associated stresses and subsequent accelerated fatigue [15]. Therefore, in the design stage, a load analysis that estimates the combined effects of wind and wave on the structure is very important to ensure the safety of the wind turbine components.

To accurately estimate the loading during the lifetime of an offshore HAWT, it is crucial to correctly include the effects of damping in the analysis. This is because damping directly affects the structural response, with the amplitude of vibrations being inversely proportional to the damping [16]. The overall damping of an offshore wind turbine is made up of structural damping, soil damping, hydrodynamic damping and aerodynamic damping. The structural damping is related to the material used. For a tubular steel tower, the structural modal damping ratio is usually less than $1 \%$ and in general a value of $0.5 \%$ is applied. Soil damping and hydrodynamic damping are usually less than structural damping [15]. Similarly, the aerodynamic damping experienced by a simple stationary structure in air is generally less than structural damping. However, this does not apply to an HAWT, where the aerodynamic damping is induced by the rotor aerodynamics and could be much higher than the structural damping $[1,11,15,17-21]$.

Although it is recognised that aerodynamic damping plays a key role in restraining vibrations in an HAWT, there is a lack of explicit recommendations on aerodynamic damping in the design guidelines [22, 23]. A recommendation published jointly by the American Wind Energy Association and the American Society of Civil Engineers [24] suggests that the design spectra for the support structure of operational turbines should be based on a total damping ratio of $5 \%$ to include aerodynamic damping. However, using a constant value for the aerodynamic damping for wind turbines of all sizes may be incorrect, as the aerodynamic design and structural configuration may vary from turbine to turbine. This will surely affect the aerodynamic damping value. In addition, as wind turbines operate in a highly unstable environment $[14,22,25]$ due to the wind turbulence and yawing, pitch and speed regulations of the wind turbine, the associated unsteady aerodynamics may lead to time-varying aerodynamic damping.

Generally, 'dynamic inflow' and 'dynamic stall' models are used to account for the unsteady aerodynamics of 
wind turbines. The dynamic inflow model considers the delay in the induced flow field reacting to the changes in the load conditions on the rotor [25]. The study was initiated in the context of helicopter aerodynamics. The most widely used model is the Pitt and Peters model [26], originally developed for an actuator disk with assumptions made concerning the distribution of inflow across the disc. This model was substantially validated in the helicopter field [27]. The model was extended by Peters and He [28] with introduction of more flow states and a fully nonlinear implementation to account for turbulence and spatial variation of the inflow. Application of the model to the Tjæreborg turbine [29] indicated that the dynamic inflow model can successfully capture the time lag effect during a fast pitching operation. On the other hand, the dynamic stall model accounts for the transient aerodynamic forces caused by the dynamic variations in the Angle Of Attack (AOA) of the blade airfoils. Because dynamic stall significantly affects the fatigue loads and ultimate loads on wind turbines, dynamic stall phenomena of pitching airfoils have been extensively studied numerically [3032] and analytically. Models used in the industry include the Boeing-Vertol model [33], the ONERA model [34], the Øye model [35] and the Beddoes-Leishman (B-L) model [36, 37]. Of these, the B-L model is the most popular and has been widely used in helicopter and wind turbine analyses. Calculation of the unsteady aerodynamic effects is important because it can correctly reflect the loads experienced by a wind turbine operating in the field. It is also important for predicting the aerodynamic damping dominated by rotor aerodynamics.

To obtain a better understanding of the aerodynamic damping, efforts have been directed to experimental measurements [9, 15, 38-41] and predictive models [1, 11, 17-21, 42, 43]. In Ref. [17], Petersen et al. estimated the aerodynamic damping for a wind turbine blade, based on a linearised, quasi-steady, 2-D analysis of a blade section. They recommended that aerodynamic damping should be taken into account during the initial design of a wind turbine. The model [17] was applied by Rasmussen et al. [18] in their parametric studies of the aerodynamic damping of airfoils. They found that both steady and unsteady airfoil data are important for aerodynamic damping, and that the structural pitch will also affect aerodynamic damping significantly. Thomsen and Petersen [43] developed a model to determine the total damping of edgewise blade vibrations, including the structural damping and aerodynamic damping, based on a description of the vibrations in terms of 'local blade whirl'. The model was validated with measurements on a wind turbine blade. Liu et al. [21] 
introduced an aerodynamic damping model for wind turbine blades based on an analysis of aerodynamic forces on a blade section. The model was incorporated into a transient simulation and it was found that aerodynamic damping greatly affects the blade vibration. These studies were focused on the aerodynamic damping of only the wind turbine blades. On the other hand, Garrad [42] proposed an aerodynamic damping model for the tower of constant-speed HAWTs. Kühn [11] simplified the derivation by Garrad [42] and presented aerodynamic damping in terms of the rate of change of the lift coefficient with respect to the AOA, the geometric shape of the blades, and the dynamic characteristics of the tower. Kühn's model also assumed a constant-speed wind turbine. However, large wind turbines are usually designed as variable-speed machines to achieve optimum energy capture below the rated wind speed. Salzmann and van der Tempel [1] pointed out that, for a variablespeed wind turbine, although the changes in rotor speed are slower than the changes in wind velocity, its effects on aerodynamic damping cannot be ignored. They then proposed a correction factor to Kühn's model. Also, they presented another model that considers the aerodynamic damping as a variation in the thrust force caused by a variation in the wind speed perpendicular to the rotor plane. Valamanesh and Myers [19] presented a closed-form solution for the aerodynamic damping of HAWT towers responding dynamically in the fore-aft and lateral directions. The model is based on the Blade Element-Momentum (BEM) theory and assumes a rigid rotor subjected to a steady and uniform wind oriented perpendicular to the rotor plane. Through simulations of a 1.5 MW wind turbine, they found that the rate of change of the lift coefficient of the blades with respect to the AOA contributes most to aerodynamic damping and that the aerodynamic damping in the fore-aft direction is much larger than that in the lateral direction. Overall, the above studies provided insights into the modelling of aerodynamic damping and the parameters that affect aerodynamic damping. Although these explorations are valuable, comprehensive studies of the effects of aerodynamic damping on the lifetime fatigue loading on the support structures of offshore HAWTs are very limited. Such studies require the incorporation of timevarying aerodynamic damping into a transient load analysis to reflect the combined effect of wind and wave loading and the dynamics of the support structure. Also, through this exercise, the influence of the aerodynamic damping on the fatigue loads can be studied quantitatively, and the performance of various aerodynamic damping estimation methods in the prediction of fatigue loads can be analysed. Such information is likely to be very helpful for the safe design of large-scale offshore HAWTs. 
In the present study, a load analysis of an offshore HAWT tower is presented. The analysis combines the calculation of aerodynamic loads, wave loads and structural responses. An aerodynamic damping model for a variable-speed wind turbine is proposed to calculate the transient aerodynamic damping with a consideration of unsteady aerodynamics. The model recommended by Salzmann and van der Tempel [1] which solves the aerodynamic damping using the BEM theory assuming steady wind conditions is also introduced. Both models are incorporated into the transient load analysis. In order to obtain a comprehensive understanding of the influence of aerodynamic damping on the fatigue loads on the offshore HAWT tower, load analysis of a 5 MW wind turbine is carried out. The effect of aerodynamic damping on the lifetime fatigue loads on the offshore wind turbine tower is then investigated. In addition, a comparison of different aerodynamic damping models is presented.

\section{Offshore HAWT tower loading}

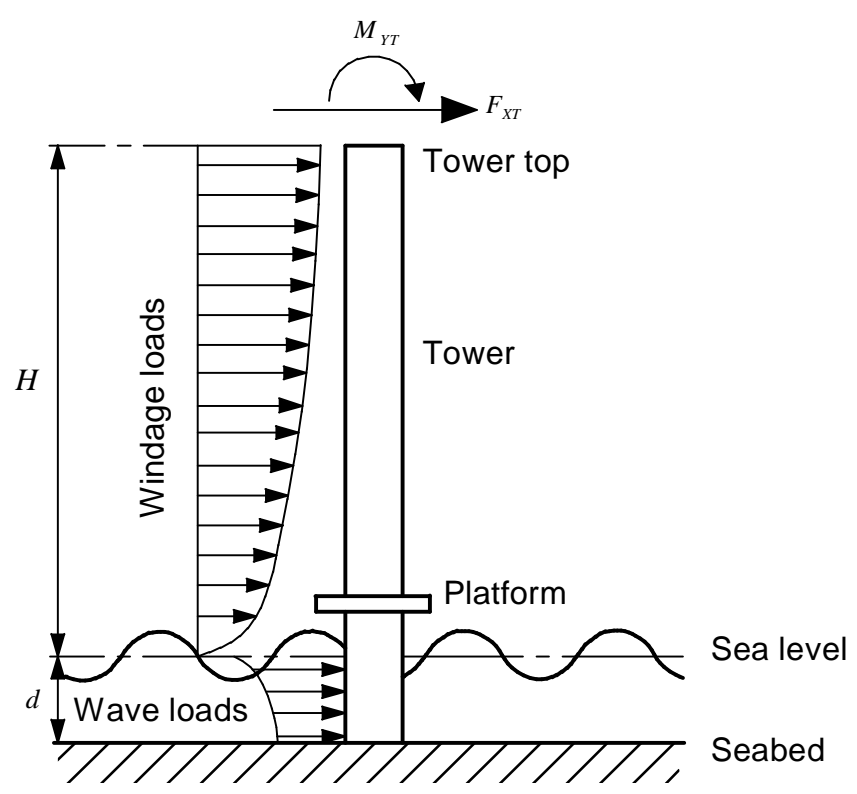

Fig. 1. Loads acting on an offshore HAWT tower.

An offshore HAWT with a tubular tower installed on a monopile foundation was studied. The HAWT tower usually has a large aspect ratio and can be treated as a cantilever. Thus it can be discretised using two-node beam elements [44] in the Finite Element (FE) model. The FE dynamic equation of motion of the tower is obtained as [44]:

$$
\mathbf{M} \ddot{\mathbf{x}}(t)+\mathbf{C} \dot{\mathbf{x}}(t)+\mathbf{K x}(t)=\mathbf{P}(t)
$$

where $\mathbf{M}$ is the mass matrix, $\mathbf{C}$ the damping matrix, and $\mathbf{K}$ the stiffness matrix; $\ddot{\mathbf{x}}(t), \dot{\mathbf{x}}(t), \mathbf{x}(t)$ are the 
acceleration, velocity and displacement vectors of the FE node respectively; $\mathbf{P}(t)$ is the time-varying load matrix.

For an offshore HAWT, the major components of the loading exerted on the tower (see Fig. 1) are the wave loads, the windage loads, the tower self-weight, and the loads acting on the tower top from the rotor and nacelle, including aerodynamic and gravitational loads. The aerodynamic damping provided by the rotor mainly affects the tower response in the fore-aft direction and only negligibly in the side-to-side direction $[9,11,19]$. Therefore, in the following sections, only the loads affecting tower deflection in the fore-aft direction are analysed.

To account for the loads and deflections, a blade coordinate system and a tower coordinate system are defined in Fig. 2. In the blade coordinate system: $Z B$ is radially along the blade axis; $X B$ is along the rotor axis, and $Y B$ is perpendicular to both blade axis and rotor axis. In the tower coordinate system: $Z T$ is directed vertically upwards; $X T$ is horizontal and pointing downwind; $Y T$ is perpendicular to both $Z T$ and $X T$.

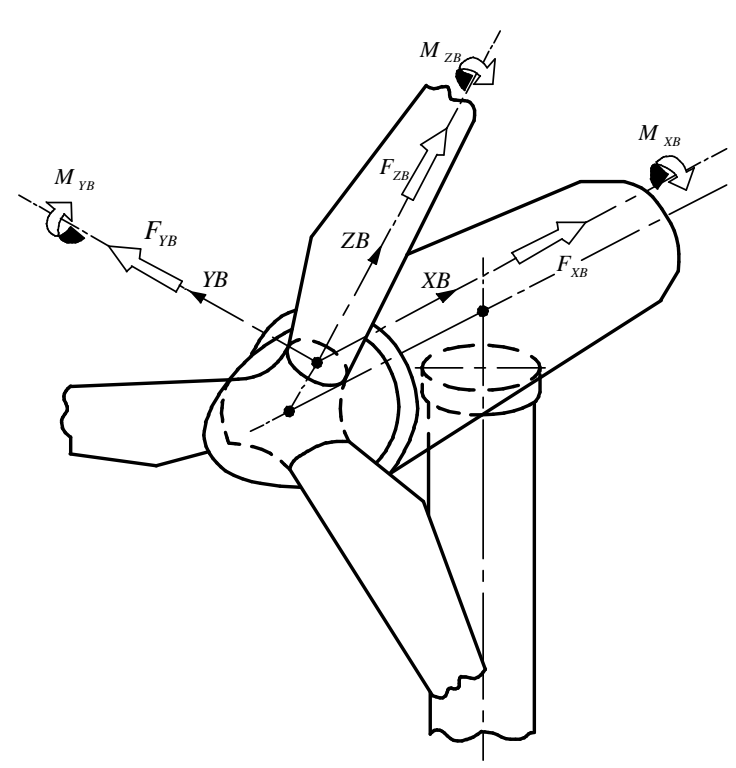

a. Blade coordinate system

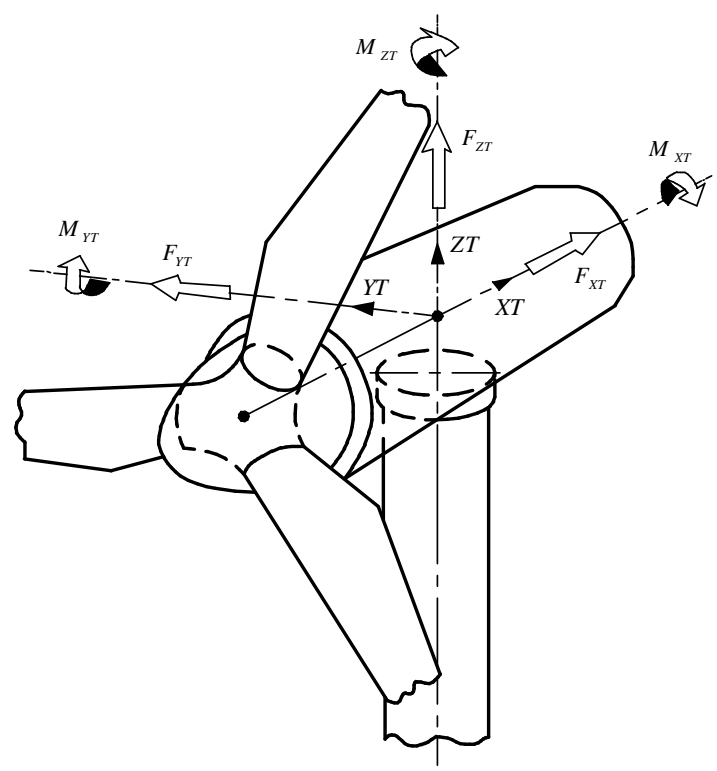

b. Tower coordinate system

Fig. 2. Coordinate systems for loads and deflections [22].

\subsection{Aerodynamic loads}

Aerodynamic loads on the wind turbine blade were calculated using the BEM theory [25, 45]. As the BEM theory was originally developed for a wind turbine operating in steady wind, it was amended by introducing the 
'dynamic inflow' [26] and 'dynamic stall' [37] models to account for the transient aerodynamics caused by wind turbulence, yawing, rotational speed regulation and pitch regulation, which are common to a wind turbine operating in the field [21].

The BEM theory is based on the 'momentum theory' and 'blade element theory'. In the momentum theory, the wind turbine rotor is considered as an energy-extracting actuator disc rotating in a stream tube [25, 45]. The axial force $T$ and torque $Q$ per unit length on the annulus of the actuator disc can then be obtained based on the conservation of momentum in both axial and rotational directions as:

$$
\begin{gathered}
\frac{\mathrm{d} T}{\mathrm{~d} r}=4 \pi \rho U^{2} r a(1-a) \\
\frac{\mathrm{d} Q}{\mathrm{~d} r}=4 \pi \rho \Omega U r^{3} a^{\prime}(1-a)
\end{gathered}
$$

where $\rho$ is the air density, $U$ the upstream wind velocity, $r$ the radial distance of the blade section from the axis of rotation, $a$ the axial flow induction factor, $a^{\prime}$ the tangential flow induction factor, and $\Omega$ the rotor angular velocity.

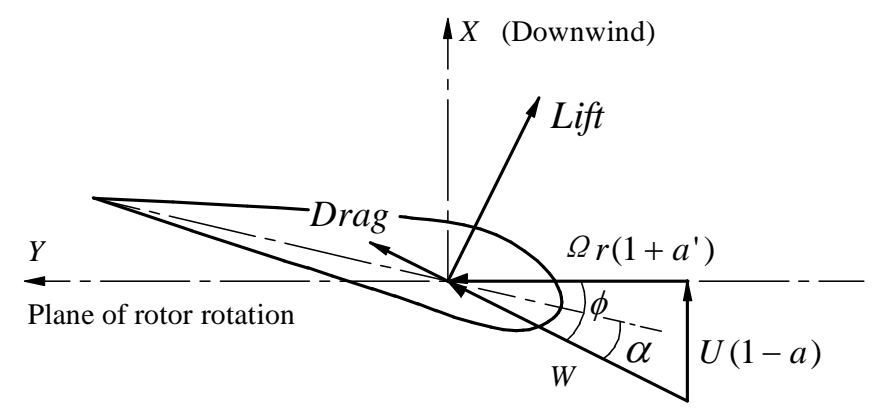

Fig. 3. Velocity diagram for a blade section.

The blade element theory is based on airfoil aerodynamics [25, 45]. Considering a blade section at radius $r$, the normal force and tangential force per unit length can be obtained as (refer to Fig. 3):

$$
\begin{aligned}
\frac{\mathrm{d} F_{X B}}{\mathrm{~d} r} & =\frac{1}{2} \rho W^{2} c\left(C_{L} \cos \phi+C_{D} \sin \phi\right) \\
\frac{\mathrm{d} F_{Y B}}{\mathrm{~d} r} & =-\frac{1}{2} \rho W^{2} c\left(C_{L} \sin \phi-C_{D} \cos \phi\right)
\end{aligned}
$$

where $W$ is the relative airflow velocity, $C_{L}$ and $C_{D}$ the lift coefficient and drag coefficient of the airfoil respectively, $\phi$ the inflow angle, and $c$ the airfoil chord length. 
Based on the blade element theory, the axial force $T$ and torque $Q$ per unit length on the annulus of the rotor are:

$$
\begin{gathered}
\frac{\mathrm{d} T}{\mathrm{~d} r}=\frac{1}{2} \rho W^{2} B c\left(C_{L} \cos \phi+C_{D} \sin \phi\right) \\
\frac{\mathrm{d} Q}{\mathrm{~d} r}=-\frac{1}{2} \rho W^{2} B c r\left(C_{L} \sin \phi-C_{D} \cos \phi\right)
\end{gathered}
$$

where $B$ is the number of blades. Eqs. (2) to (7) can be iteratively solved using the Newton-Raphson method.

The momentum theory assumes that the induced velocity flow field reacts instantaneously to the changes in blade loading, while in reality these changes take a finite time to change the induced flow field [25]. The dynamics associated with this process is commonly referred to as 'dynamic inflow', which is taken into account using the model based on the work of Pitt and Peters [26]. The model is applied at actuator annuli level and consequently Eq. (2) is amended as [21]:

$$
\frac{\mathrm{d} T}{\mathrm{~d} r}=4 \pi \rho U^{2} r a(1-a)+8 \rho U r^{2} \dot{a}
$$

Eq. (8) can then replace Eq. (2) in the momentum theory. It is evident that it introduces a time lag into the calculation of inflow which is dependent on the radial station.

When a wind turbine is operating in steady conditions, the static values of lift and drag coefficients of the airfoils can be used in Eqs. (4) and (5) to estimate the blade loads. However, in reality wind turbines work in highly unsteady conditions. Dynamic variations of the AOA of the airfoil due to the wind turbulence, yawing, pitch and rotational speed regulation will result in transient airfoil aerodynamics which can considerably affect the loading on the blade. To account for these effects, the B-L dynamic stall model $[36,37]$ is employed to calculate the transient airfoil aerodynamics. As wind turbine airfoils are relatively thick and work at low Mach numbers [46], the flow can be assumed incompressible, with negligible effect of leading edge flow separation. Therefore, two elements of the original B-L model are utilised: 1) the indicial response functions for the modelling of a fully attached flow; 2) the time-lagged Kirchhoff formulation for the modelling of trailing edge separation and vortex lift.

The B-L model is based on airfoil indicial response, which produces the normal force coefficient $C_{N}$ as a function of time for a step change in the AOA. The increment in $C_{N}$ due to a step change in AOA $\Delta \alpha$ is divided 
into two parts, a non-circulatory part $C_{N}{ }^{I}$, and a circulatory part $C_{N}{ }^{C}$ :

$$
\begin{aligned}
\Delta C_{N}^{C} & =C_{N \alpha} \phi_{\alpha}^{C} \Delta \alpha \\
\Delta C_{N}^{I} & =\frac{4}{M_{a}} \phi_{\alpha}^{I} \Delta \alpha
\end{aligned}
$$

where $C_{N \alpha}$ is the slope of the normal force coefficient, $M_{a}$ the Mach number, $\phi_{\alpha}{ }^{C}$ the circulatory indicial function, and $\phi_{\alpha}{ }^{I}$ the non-circulatory indicial function. In the B-L model the chord wise force coefficient $C_{C}$ response is based on the circulatory part of $C_{N}$. The airfoil attached flow response due to a general AOA history is calculated from the superposition of individual indicial responses for each step.

The attached flow response is then modified based on the position of the effective flow separation point on the low pressure side of the airfoil. Flow separation from the airfoil results in a loss of circulation around the airfoil, reducing aerodynamic coefficients from the attached flow values. The separation point is given by $f=$ $x / c$, where $x$ is the point of flow separation measured from the leading edge, and $c$ the airfoil chord length. An approximation to Kirchhoff theory used by B-L relates $C_{N}$ to the separation point is given as:

$$
C_{N}=C_{N \alpha}\left(\alpha-\alpha_{0}\right)\left(\frac{1+\sqrt{f}}{2}\right)^{2}
$$

where $\alpha_{0}$ is the zero-lift AOA.

The static effective separation point is calculated from static $C_{N}$ data by solving Eq. (11). The effective separation point versus AOA is then curve-fitted using an exponential function. In the B-L model an empirically derived first order lag is applied to the movement of the effective separation point to account for the time lag in movement of the separation point during unsteady conditions.

The final main component of the model represents the vortex build-up and shedding that occurs during dynamic stall. The vortex lift contribution is empirically modelled as an excess circulation in the vicinity of the airfoil. The magnitude of the increase in lift is based on the difference between the attached flow $C_{N}$, and the $C_{N}$ value obtained from the Kirchhoff equation. Empirically derived time constants are used to govern the growth, decay, and motion of the vortex. A non-dimensional time constant tracks the position of the vortex across the airfoil. As the vortex reaches the trailing edge the strength is allowed to decay exponentially. 
The lift coefficient $C_{L}$ and drag coefficient $C_{D}$ are then calculated from resolving $C_{N}$ and $C_{C}$ into components normal and parallel to the velocity direction, and adding the minimum drag $C_{D 0}$.

$$
\begin{gathered}
C_{L}=C_{N} \cos \alpha+C_{C} \sin \alpha \\
C_{D}=C_{N} \sin \alpha-C_{C} \cos \alpha+C_{D 0}
\end{gathered}
$$

Using the B-L model, the unsteady lift coefficient $C_{L}$ and drag coefficient $C_{D}$ can then be obtained during the time-domain simulation and consequently applied to Eqs. (4) and (5).

Through integrations of Eqs. (4) and (5), the normal and tangential forces over the entire blade can be obtained and transmitted to the tower top. Considering the number of blades $B$, the rotor azimuth angle $\theta$, the shaft tilt angle $\chi$, and the rotor cone angle $\beta_{0}$, the force exerted on the tower top in the fore-aft direction (see Fig. 1) may be given as:

$$
F_{X T}=B F_{X B} \sin \chi \sin \theta+B F_{Y B}\left(\cos \beta_{0} \cos \chi-\sin \chi \sin \beta_{0} \cos \theta\right)
$$

\subsection{Windage and gravitational loads}

For a tubular tower, the windage load per unit length at height $h$ in the fore-aft direction may be simply given as [47]:

$$
\frac{\mathrm{d} F_{W}}{\mathrm{~d} h}=\frac{1}{2} \rho U^{2} D_{t} C_{D}
$$

where $D_{t}$ is the outer diameter of the tower station and $C_{D}$ the aerodynamic drag coefficient of the tower station.

To account for the gravitational loads which will affect the tower deflection in the fore-aft direction, the rotor together with the nacelle is treated as a point mass. If the sum of their masses is $m_{s}$ and the centre of mass is at $\left(x_{s}, y_{s}, z_{s}\right)$ in the tower coordinate system, the tower top moment $M_{Y T}$ (see Fig. 1) can be obtained as:

$$
M_{Y T}=m_{s} g x_{s}
$$

where $g$ is the gravitational acceleration.

\subsection{Wave loads}

The hydrodynamic loading on offshore structures consists of several components, including viscous drag loading, inertia loading, dynamic pressure loading, etc. [11]. If a loaded member is small compared with the water 
wavelength, the water particle motions are only locally affected by the member and the forces can be calculated from the drag and inertia components using Morison's equation $[47,48]$. In this study, the diameter of the crosssection of the tower and pile is considered to be less than 1/5 of the wavelength. In this case, using Morison's equation to estimate wave loading is adequate and the other components can be neglected. Thus the horizontal force on the structure per unit length at level $z$ can be expressed as [48]:

$$
\frac{\mathrm{d} F_{w}}{\mathrm{~d} z}=\frac{1}{4} \pi \rho_{w} D_{t}^{2} \dot{U}_{w} C_{M}+\frac{1}{2} \rho_{w} D_{t}\left|U_{w}\right| U_{w} C_{D}
$$

where $z$ is the depth below the mean water surface, $\rho_{w}$ the density of water, $C_{M}$ the hydrodynamic inertia coefficient, $C_{D}$ the hydrodynamic drag coefficient, and $U_{w}$ the horizontal wave-induced velocity.

The horizontal wave-induced velocity and acceleration can be estimated using the first-order linear wave theory [47]:

$$
\begin{gathered}
U_{w}=A_{w} \omega \frac{\cosh [k(z+d)]}{\sinh (k d)} \sin (\omega t) \\
\dot{U}_{w}=A_{w} \omega^{2} \frac{\cosh [k(z+d)]}{\sinh (k d)} \cos (\omega t)
\end{gathered}
$$

where $A_{w}$ is the wave amplitude, $\omega$ the angular frequency, $k$ the wave number, $d$ the water depth, and $t$ the time. In practice, waves are irregular in shape, varying in height, length and speed of propagation, and may approach an offshore wind turbine from one or more directions simultaneously. The features of a real sea can be reflected by describing a sea state by means of a stochastic wave model. The stochastic wave model represents the sea state as the superposition of a number of small individual frequency components, each of which is a periodic wave with its own amplitude, frequency and direction of propagation; the components have random phase relationships to each other. In this study, a design sea state is described by the JONSWAP spectrum [22, 49]:

$$
S_{\zeta}(f)=\alpha_{1} H_{s}^{2} T_{p}\left(\frac{f}{f_{p}}\right)^{-5} \exp \left[-1.25\left(\frac{f}{f_{p}}\right)^{-4}\right] \gamma^{\beta_{1}}
$$

where $f$ is the wave frequency, $H_{s}$ the significant wave height, $f_{p}=1 / T_{p}, T_{p}$ the peak wave period, $\gamma$ the JONSWAP peak-shape parameter, and 


$$
\alpha_{1}=\frac{0.0624}{0.23+0.0336 \gamma-\frac{0.185}{1.9+\gamma}}
$$

and

$$
\beta_{1}=\exp \left[-0.5\left(\frac{f-f_{p}}{f_{p} \sigma}\right)^{2}\right],
$$

where $\sigma=0.07$ for $f \leq f_{p}$ and $\sigma=0.09$ for $f>f_{p}$.

\section{Aerodynamic damping}

\subsection{The mechanism of aerodynamic damping of a HAWT tower}

Fig. 4 shows the generation of aerodynamic damping. If the tower top experiences a perturbation in the wind direction with velocity $\dot{x}_{\text {top }}$, the apparent out-of-plane velocity component of a blade section, $U(1-a)$, will be reduced by $\dot{x}_{\text {top }}$ according to the BEM theory (see Fig. 4 a). This will lower the AOA, $\alpha$, resulting in a reduction of the lift force, $\mathrm{d} L$, and the drag force, $\mathrm{d} D$, for the assumed 'attached flow' conditions. Consequently, the thrust force, $\mathrm{d} F_{X B}$, is reduced by $\Delta \mathrm{d} F_{X B}$, acting as a resistance to the downwind motion. Likewise, a perturbation of the tower top against the wind direction increases both the AOA and the thrust force (see Fig. 4c), while the thrust force increment also resists the initial perturbation. In either situation the alteration of the thrust force opposes the disturbing tower top motion, and this is experienced as aerodynamic damping [11]. 

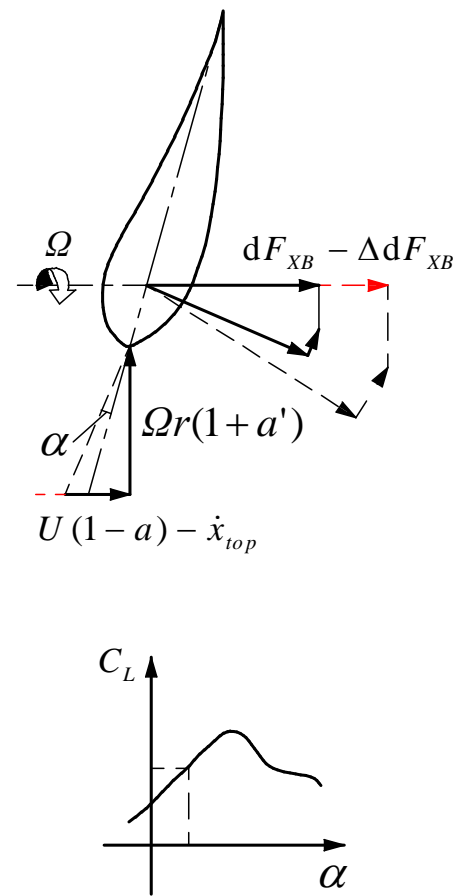

a. tower top motion in wind direction
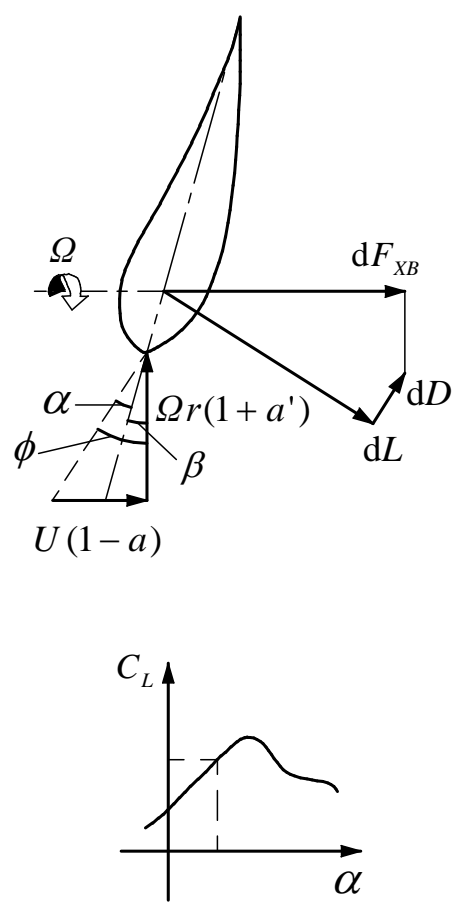

b. no tower top motion
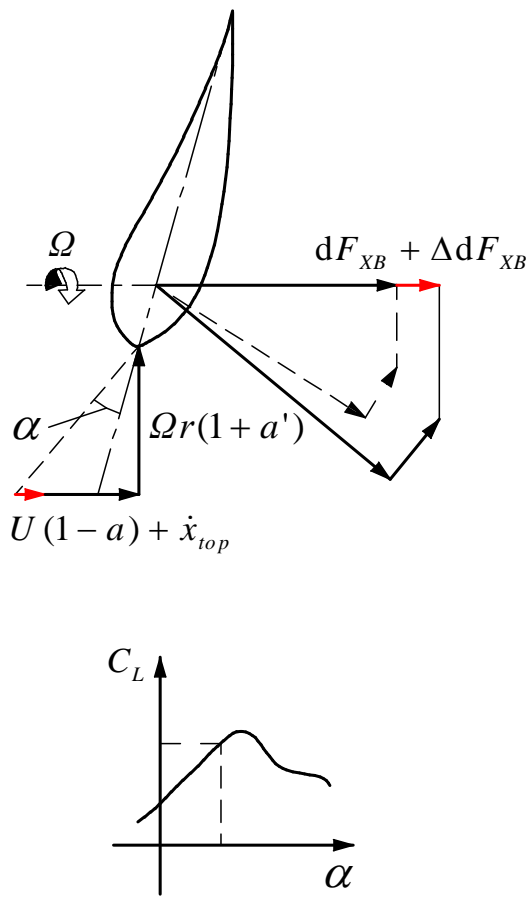

c. tower top motion against wind direction

Fig. 4. Velocity and force diagram for vibrating blade according to tower top motion, adapted from [11].

When the airfoil is stalled, the aerodynamic damping can be lower or even negative, meaning that the flow supplies energy to the tower. This may result in a potentially self-exciting system if the aerodynamic damping supplied by the rotor becomes negative. Stall-induced vibration will occur when the energy cannot be removed through structural damping, leading to damage to the structure $[17,50,51]$.

Aerodynamic damping also occurs during lateral motion of the tower top, but the interaction is much less pronounced. In a normal sea state, the water waves usually propagate in the direction of the wind. It has been demonstrated that this assumption is conservative and thus it is acceptable to assume that the wind and waves are aligned [22]. Therefore, we would expect that the aerodynamic damping will reduce the tower vibrations caused by waves and consequently alleviate the tower fatigue loads.

\subsection{Aerodynamic damping model}

As mentioned above, the aerodynamic damping is induced by the interaction between structural motion and rotor aerodynamics. Accordingly, a model can be derived based on an analysis of the rotor aerodynamics incorporating the tower top motion. 
The derivation can be started by considering a constant-speed wind turbine $[1,42]$. Considering the velocity components of an airfoil shown in Fig. 4, let $U_{r}=\Omega r\left(1+a^{\prime}\right)$ and $U_{d}=U(1-a) \pm \dot{x}_{\text {top }}$. Eq. (4) may be reduced to:

$$
\frac{\mathrm{d} F_{X B}}{\mathrm{~d} r}=\frac{1}{2} \rho U_{r}^{2} C_{L} C
$$

using the following assumptions:

- $\quad$ small inflow angle $\phi(\cos \phi \approx 1)$

- $\quad$ high tip speed ratio $\left(U_{r}>>U_{d}\right)$

- $\quad$ attached flow $\left(C_{L}>>C_{D}\right)$

As $U_{r} \gg U_{d}$, one can assume

$$
\phi \approx \frac{U_{d}}{U_{r}}
$$

A constant-speed HAWT gives:

$$
\mathrm{d} \phi \approx \frac{\mathrm{d} U_{d}}{U_{r}}
$$

The slope of the lift coefficient can be written as $C_{L}{ }^{\prime}=\mathrm{d} C_{L} / \mathrm{d} \alpha$. While the inflow angle $\phi=\alpha+\beta$ and the twist angle $\beta$ is a constant, one can get

$$
\mathrm{d} C_{L}=C_{L}^{\prime} \mathrm{d} \phi=C_{L}{ }^{\prime} \frac{\mathrm{d} U_{d}}{U_{r}}
$$

Differentiation of Eq. (21) gives

$$
\mathrm{d}\left(\frac{\mathrm{d} F_{X B}}{\mathrm{~d} r}\right)=\frac{1}{2} \rho U_{r}^{2} c \mathrm{~d} C_{L}=\frac{1}{2} \rho U_{r} c C_{L}^{\prime} \mathrm{d} U_{d}
$$

As shown in Fig. 4, the change in the apparent axial wind speed $U_{d}$ is due to changes in the wind speed and the structural motion. Therefore

$$
\mathrm{d} U_{d}=u-\dot{x}
$$

where $u$ is the change in the axial wind speed and $\dot{x}$ the structural velocity whose sign is positive when aligned with the wind. 
Eq. (25) can be rewritten as:

$$
T^{\prime}=\mathrm{d}\left(\frac{\mathrm{d} F_{X B}}{\mathrm{~d} r}\right)=\frac{1}{2} \rho U_{r} c C_{L}^{\prime}(u-\dot{x})
$$

For a 1-degree of freedom mass-spring system, the equation of motion $m \ddot{x}+K x=T^{\prime}$ applies and can be rewritten as:

$$
m \ddot{x}+\frac{1}{2} \rho U_{r} c C_{L}^{\prime} \dot{x}+K x=\frac{1}{2} \rho U_{r} c C_{L}^{\prime} u
$$

Eq. (28) suggests that the aerodynamic damping per unit length is

$$
\frac{\mathrm{d} c_{a}}{\mathrm{~d} r}=\frac{1}{2} \rho U_{r} c C_{L}^{\prime}
$$

The aerodynamic damping of the entire rotor can then be obtained by integration of Eq. (29) along the blade:

$$
c_{a}=\frac{B \rho \Omega}{2} \int_{R_{0}}^{R} C_{L}{ }^{\prime} c r \mathrm{~d} r
$$

where $R_{0}$ is the blade root radius, and $R$ the rotor radius.

Consequently, the aerodynamic damping ratio for the $n^{\text {th }}$ mode can be defined as:

$$
\xi_{n}=\frac{c_{a}}{2 M_{n} \omega_{n}}=\frac{B \rho \Omega}{4 M_{n} \omega_{n}} \int_{R_{0}}^{R} C_{L}{ }^{\prime} c r \mathrm{~d} r
$$

where $M_{n}$ is the $n^{\text {th }}$ modal mass of the tower, and $\omega_{n}$ the $n^{\text {th }}$ natural frequency of the tower.

For a variable-speed HAWT, the change in wind speed results in the change of rotor speed, thus Eq. (23) no longer applies and should be replaced by:

$$
\mathrm{d} \phi=\mathrm{d}\left(\frac{U_{d}}{U_{r}}\right)
$$

Although the change in rotor speed is slow, it cannot be neglected. To simplify the derivation, a correction factor $b$ is introduced and Eq. (32) is changed to

$$
\mathrm{d} \phi=b \frac{\mathrm{d} U_{d}}{U_{r}}
$$

For a variable-speed HAWT, Eq. (31) can then be replaced by 


$$
\xi_{n}=\frac{B \rho \Omega}{4 M_{n} \omega_{n}} \int_{R_{0}}^{R} C_{L}^{\prime} b c r \mathrm{~d} r
$$

It should be noted that the above derivation is based on the assumption that the drag is negligible. At high wind speeds near the cut-out wind speed, the drag term may be large enough to considerably contribute to the thrust, and thus can no longer be neglected. The larger drag term will lead to increased aerodynamic damping. Therefore, using Eq. (34) is an approximation and may under-predict the aerodynamic damping at high wind speeds.

In Ref. [1], Salzmann and van der Tempel proposed an alternative method to calculate the aerodynamic damping as the increase in the thrust per unit increase in the wind speed:

$$
c_{a}=\frac{\mathrm{d} T}{\mathrm{~d} U}
$$

Solving Eq. (34) requires the solution of the BEM theory for each wind speed to find the derivative of the lift coefficient over the AOA, including the steady-state induction factor for that AOA. The correction factor $b$ also needs to be determined for each wind speed using non-linear time domain load simulations. Compared to Eq. (34), solution of Eq. (35) is much more straightforward if the objective is to calculate the aerodynamic damping as the rate of change of thrust with respect to wind speed.

\section{Results and discussion}

In order to investigate the effects of aerodynamic damping on the tower loading, load analysis of a 5MW offshore HAWT was carried out. Table 1 shows the configuration of the wind turbine. The structural damping ratio was chosen as $0.5 \%$, while in this study, the foundation in the sea bed and the pile in the water are assumed to be relatively rigid, so that soil damping and hydrodynamic damping could be neglected.

Table 1 Parameters of the test HAWT

\begin{tabular}{ll}
\hline Parameter & Value \\
\hline Wind turbine class & IEC IA \\
\hline
\end{tabular}




\begin{tabular}{ll}
\hline Rotor diameter $(\mathrm{m})$ & 118 \\
Blade length $(\mathrm{m})$ & 57 \\
Number of blades & 3 \\
Hub height $(\mathrm{m})$ & 81 \\
Rated wind speed $\left(\mathrm{m} \mathrm{s}^{-1}\right)$ & 12.3 \\
Rotational speed $\left(\mathrm{r} \mathrm{min}^{-1}\right)$ & $7.5-13.9$ \\
Tower height $(\mathrm{m})$ & 79 \\
Tower base diameter $(\mathrm{m})$ & 5.5 \\
Tower top diameter $(\mathrm{m})$ & 3.8 \\
Tower material & $\mathrm{Q}-345$ \\
Structural damping ratio & $0.5 \%$ \\
Water depth $(\mathrm{m})$ & 20 \\
\hline
\end{tabular}

To facilitate the structural dynamics solution, the aerodynamic damping needs to be estimated in advance. The two methods described by Eq. (34) (Method A) and Eq. (35) (Method B) respectively were used to evaluate the aerodynamic damping. As mentioned above, if Method A is used, transient load simulations need to be carried out for each wind speed to find out the derivative of the lift coefficient and the induction factor. More importantly, the correction factor $b$ can be determined for each wind speed through the simulations.

According to HAWT design regulations [22, 23], turbulent wind fields are required for the load simulation. Therefore, the aerodynamic damping of the tower structure under turbulent winds with different average wind speeds should be obtained beforehand. Fig. 5 shows the longitudinal component of a turbulent wind used for simulation with a $12 \mathrm{~m} \mathrm{~s}^{-1}$ average wind speed. The obtained relationship between $\mathrm{d} \phi$ and $\mathrm{d} U_{d} / U_{r}$ at a blade section $35.88 \mathrm{~m}$ from the hub centre when operating under this turbulent wind is shown in Fig. 6a. This can be used to determine the correction factor $b$ in Eq. (34) when Method A is used [42]. It is found that linear regression of the data points gives a straight line passing almost exactly through the origin. Thus the slope of the red line in Fig. $6 \mathrm{a}$ is the correction factor $b$ in Eq. (34) at this blade section for a $12 \mathrm{~m} \mathrm{~s}^{-1}$ wind. Through simulations using a number of turbulent winds with different mean wind speeds, the relationship between the correction factor $b$ and the mean wind speed at different blade sections can be obtained. 


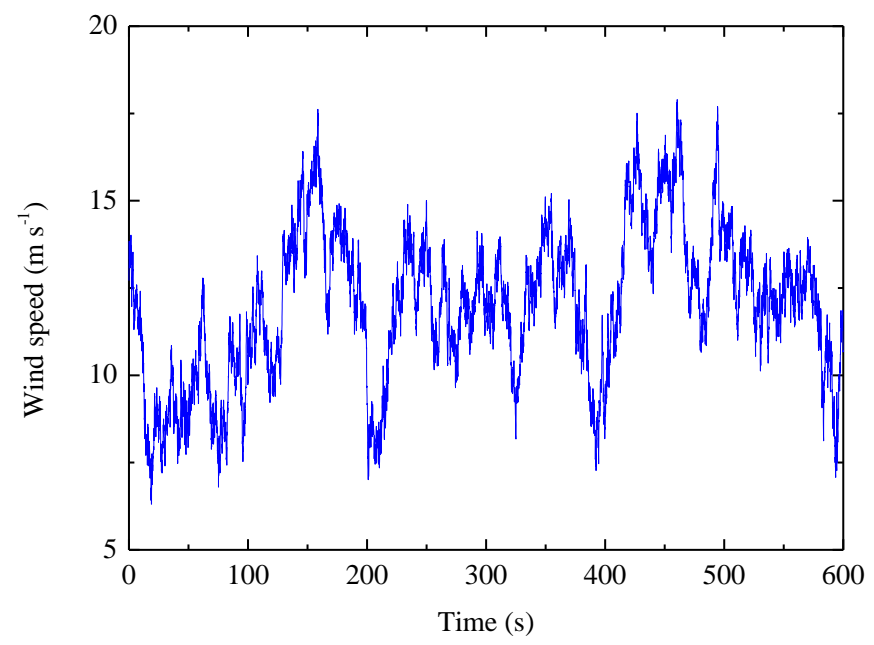

Fig. 5. Longitudinal wind speed at hub height of a $12 \mathrm{~m} \mathrm{~s}^{-1}$ turbulent wind.

Fig. $6 \mathrm{~b}$ shows the correction factor $b$ as a function of wind speed at four blade stations. It is found that higher wind speed corresponds to smaller correction factor, implying more correction. Also, the blade section closer to the hub centre needs more correction. Within the normal operational wind conditions, the correction factor deviates considerably from unity in most cases, suggesting that the correction factor should be taken into consideration to determine the aerodynamic damping of a variable-speed wind turbine.

a. Linear regression to determine $b$

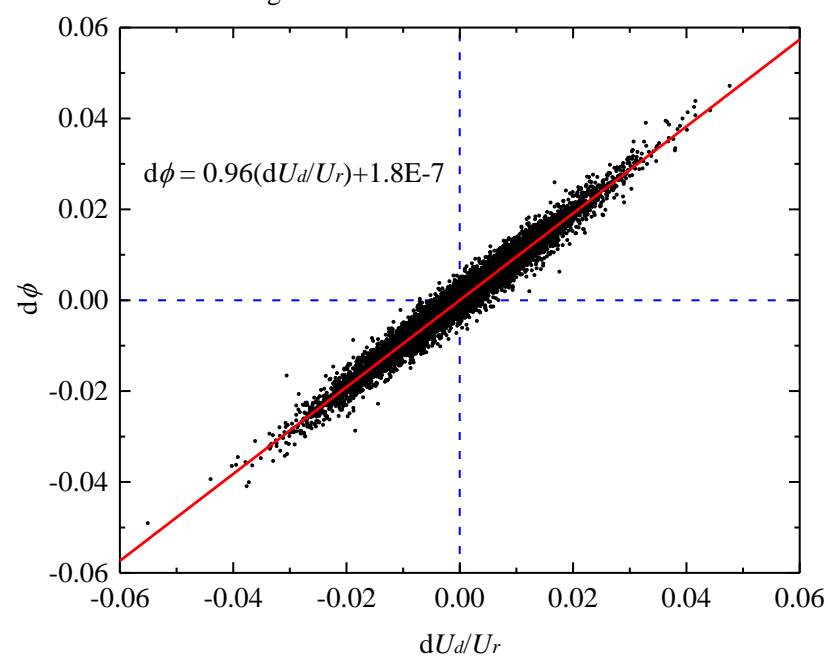

b. $b$ as a function of wind speed and radius

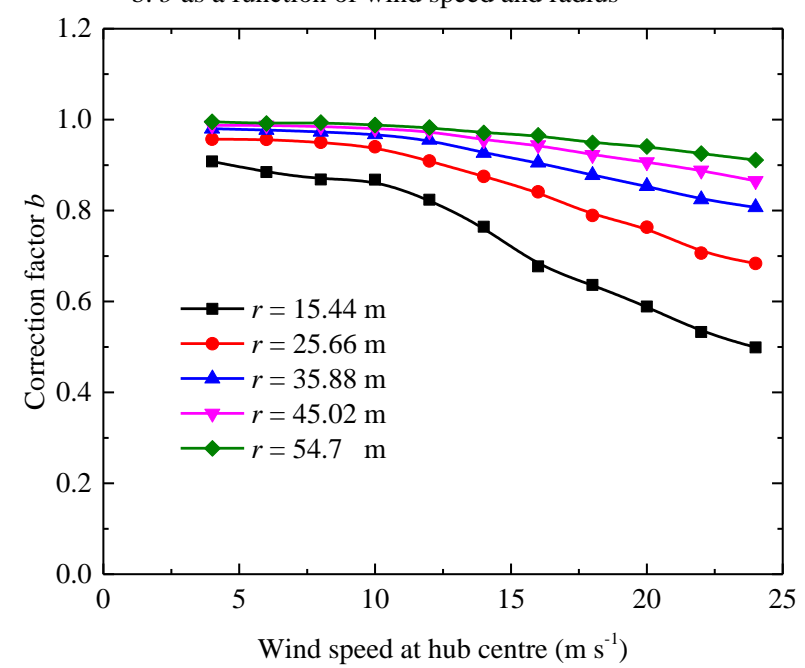

Fig. 6. Determination of correction factor $b$.

When the correction factor is determined, it can be applied to the calculation of aerodynamic damping during transient simulation. Fig. 7 shows the time histories of the modal aerodynamic damping ratio of the tower during power production under four turbulent winds, obtained by Method A. It is found that the aerodynamic damping is time-varying and presents considerable fluctuation under turbulent wind fields. This is mainly due to the 
fluctuation of the wind velocity and the corresponding unsteady aerodynamic forces experienced by the blades. Fig. 7 also shows that the fluctuation of the aerodynamic damping is more significant at wind speeds of $8 \mathrm{~m} \mathrm{~s}^{-1}$ and $12 \mathrm{~m} \mathrm{~s}^{-1}$. This is because, for this wind turbine, there is rotational speed regulation for wind speed from 5 to $9 \mathrm{~m} \mathrm{~s}^{-1}$, and the aerodynamic damping is proportional to the aerodynamic damping according to Eq. (34). It is also found that, below the rated wind speed, the aerodynamic damping increases with the wind speed. The average values of the modal aerodynamic damping ratio for wind speeds of 4,8 and $12 \mathrm{~m} \mathrm{~s}^{-1}$ are $2 \%, 3.2 \%$ and $3.4 \%$ respectively. Above the rated wind speed, the aerodynamic damping will slightly reduce. The average modal aerodynamic damping ratio for $16 \mathrm{~m} \mathrm{~s}^{-1}$ wind speed is $3.1 \%$.
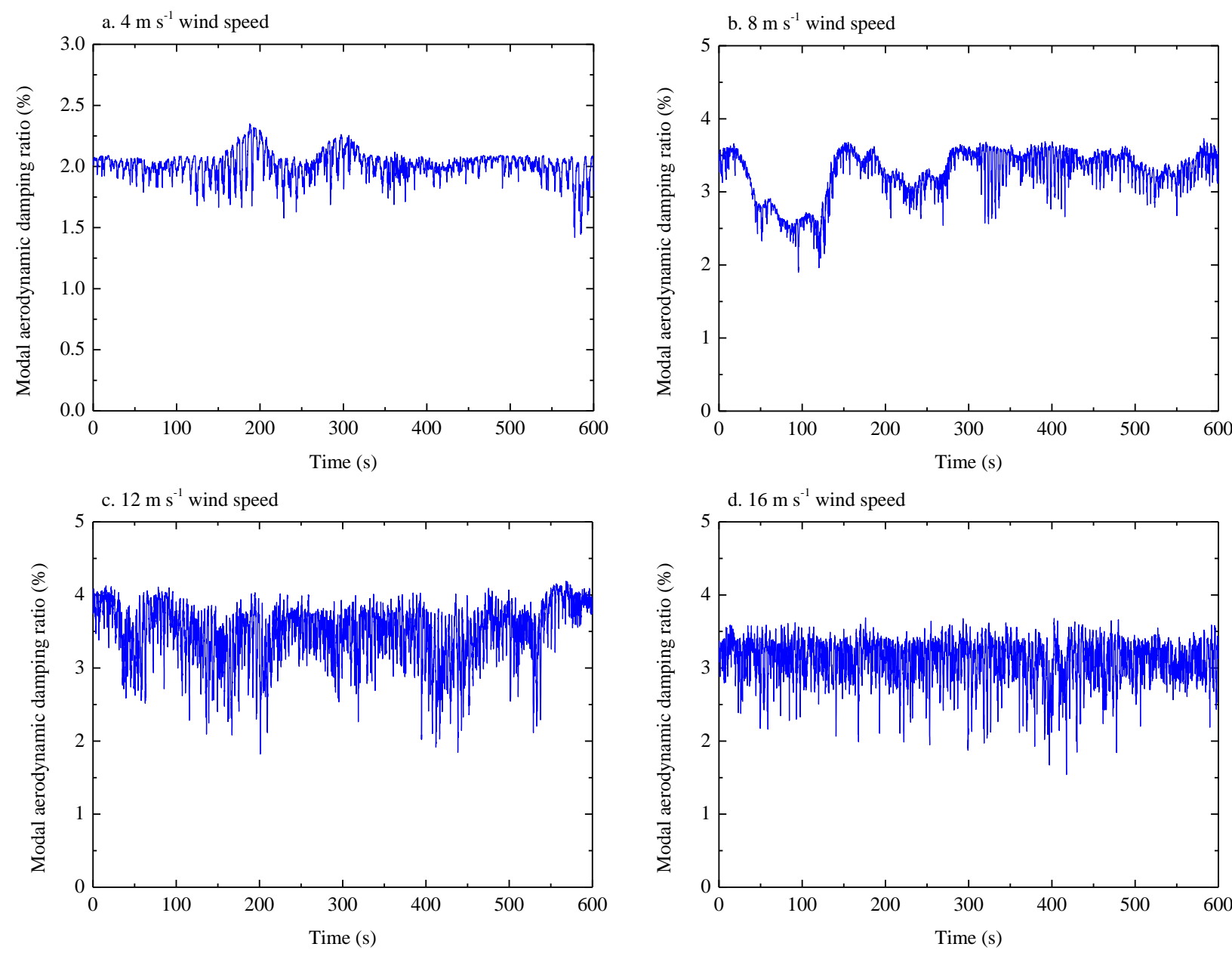

Fig. 7. Time history of the modal aerodynamic damping ratio of the tower obtained using Method A.

The calculation of aerodynamic damping using Method B is more straightforward, as only the solution of BEM theory under steady wind is required and it does not estimate the aerodynamic damping at airfoil level. Fig. 8 shows the modal aerodynamic damping ratio obtained using Method B as a function of wind speed. It is found that with the increase of the wind speed, the modal aerodynamic damping ratio increases to its maximum value 
of $5.7 \%$ at $9 \mathrm{~m} \mathrm{~s}^{-1}$ wind speed. This is also mainly due to the rotational speed regulation as mentioned above. After an initial sharp drop from the maximum value, the aerodynamic damping will maintain relatively stable for wind speed above the rated. The values of modal aerodynamic damping ratio for $4,8,12$ and $16 \mathrm{~m} \mathrm{~s}^{-1}$ wind speed are 2\%, 5.4\%, 3.8\% and 3.5\% respectively, mostly higher than that obtained by Method A. When using Method B to estimate the aerodynamic damping in a time domain simulation, the instantaneous aerodynamic damping value can be determined as a function of the instantaneous wind speed at the hub centre, according to Fig. 8 .

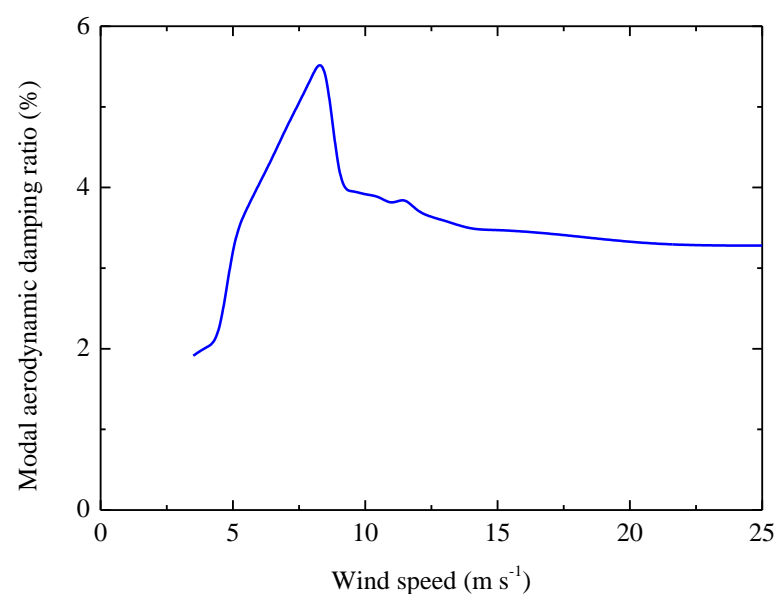

Fig. 8. Modal aerodynamic damping ratio as a function of wind speed, obtained using Method B.

In the solution of the equation of motion, the overall damping ratio of the tower was introduced by superposition of aerodynamic and structural damping ratios. Eq. (1) was solved in the time domain using the Newmark method [44]. The tower load calculation was carried out through time-domain simulation combining the aerodynamics, hydrodynamics and structural dynamics sub-systems.

A power production load case was simulated using the $12 \mathrm{~m} \mathrm{~s}^{-1}$ turbulent wind (Fig. 5). Fig. 9 shows a comparison between the time series of tower-top deflection with and without the effect of aerodynamic damping. The red curve shown in Fig. 9 was obtained using the aerodynamic damping value calculated by Method A. For clarity, only the tower top deflection results between $0 \mathrm{~s}$ and $300 \mathrm{~s}$ are displayed. It is clear that the aerodynamic damping significantly affects the tower deflection by reducing the vibration amplitude. In the time period shown in Fig. 9, the average vibration amplitude is reduced from $1.94 \mathrm{~m}$ to $0.22 \mathrm{~m}$ if the aerodynamic damping is considered. Therefore, in the wind turbine design procedure, in order to predict accurate tower deflection and fatigue load, it is very important to take into account the aerodynamic damping. It should also be noted that the tower of a largescale HAWT undergoes considerable deflection in the fore-aft direction, even if it is operating in an ordinary 
turbulent wind field. In this case, the maximum tower top deflection can reach nearly $0.8 \mathrm{~m}$ (considering aerodynamic damping), which may be big enough to influence the structural stability and turbine security, thus we should sufficiently account for the dynamic response of the tower in the design stage.

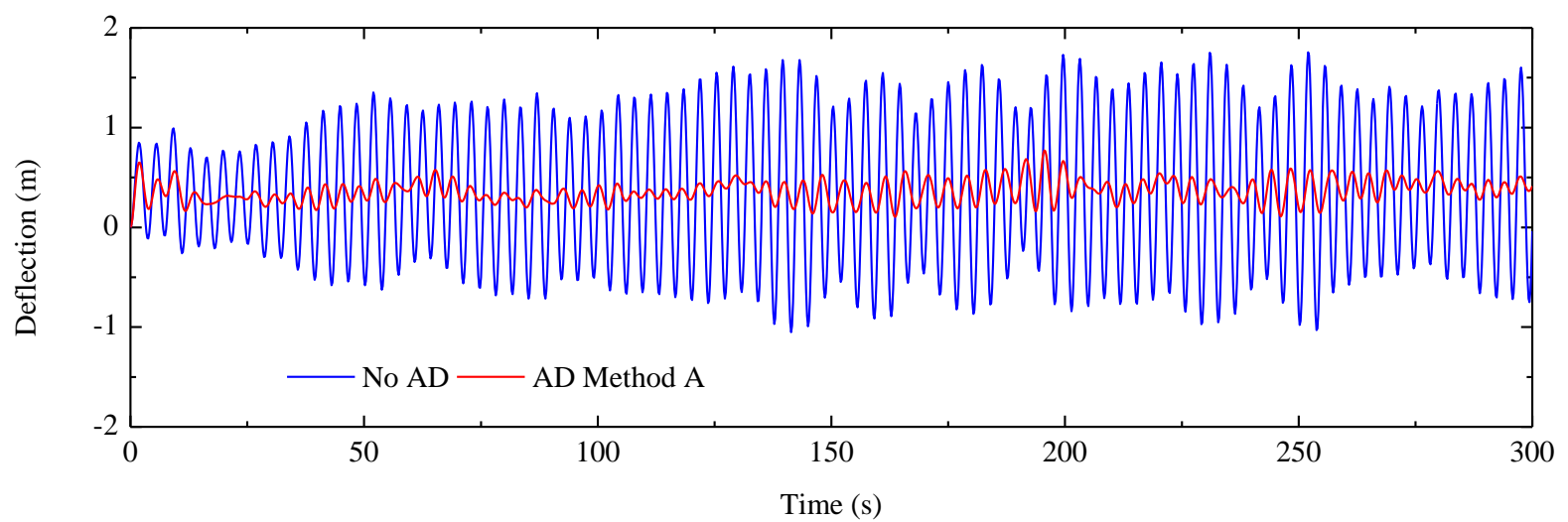

Fig. 9. Tower top deflection during power production (12 $\mathrm{m} \mathrm{s}^{-1}$ turbulent wind field used, AD: aerodynamic damping)

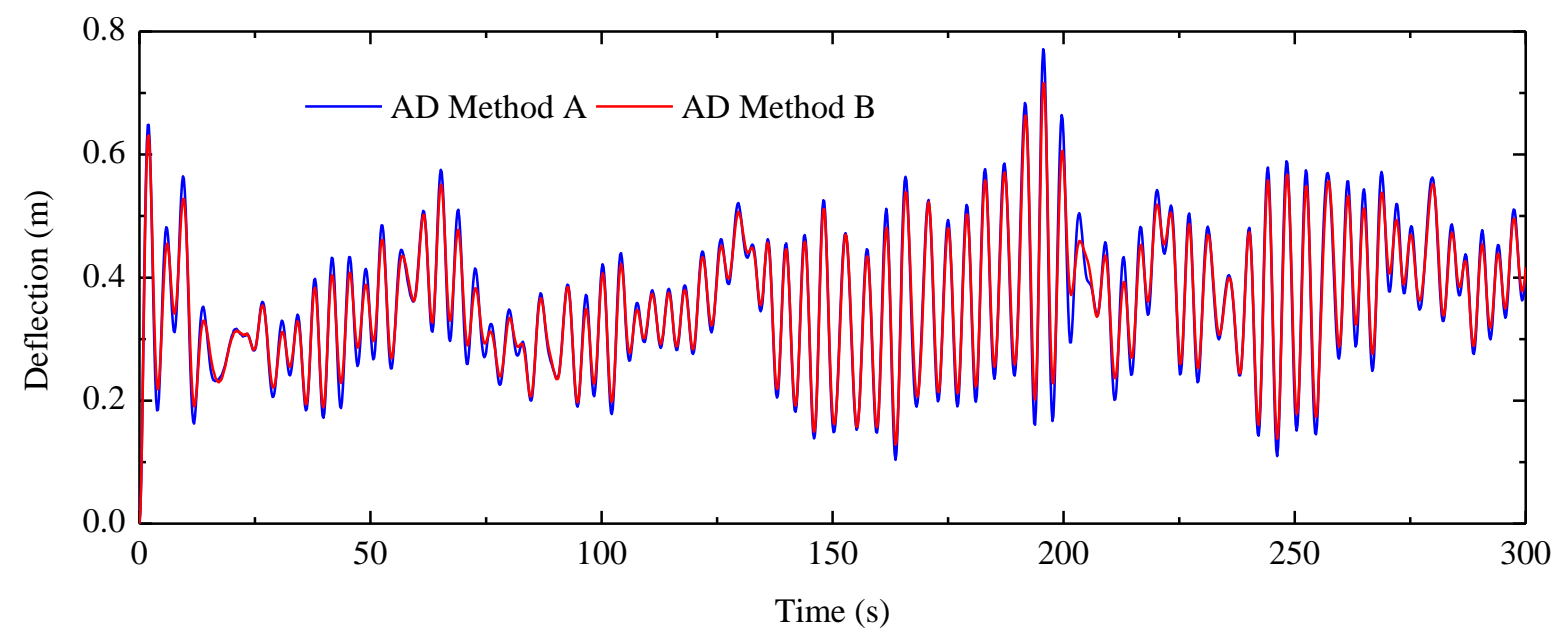

Fig. 10. Tower top deflection when considering aerodynamic damping ( $12 \mathrm{~m} \mathrm{~s}^{-1}$ turbulent wind field used)

The same load case was also simulated using aerodynamic damping as estimated by Method B. Fig. 10 shows a comparison of the tower top deflections obtained using Methods A and B. It is found that when using Method B to calculate the aerodynamic damping, the vibration amplitude of the tower top is under-estimated. In this case, the average vibration amplitude of the tower top is reduced by about $16 \%$. This agrees with the finding that the aerodynamic damping estimated by Method B at $12 \mathrm{~m} \mathrm{~s}^{-1}$ wind speed is higher than that the time-average value estimated by Method A. 

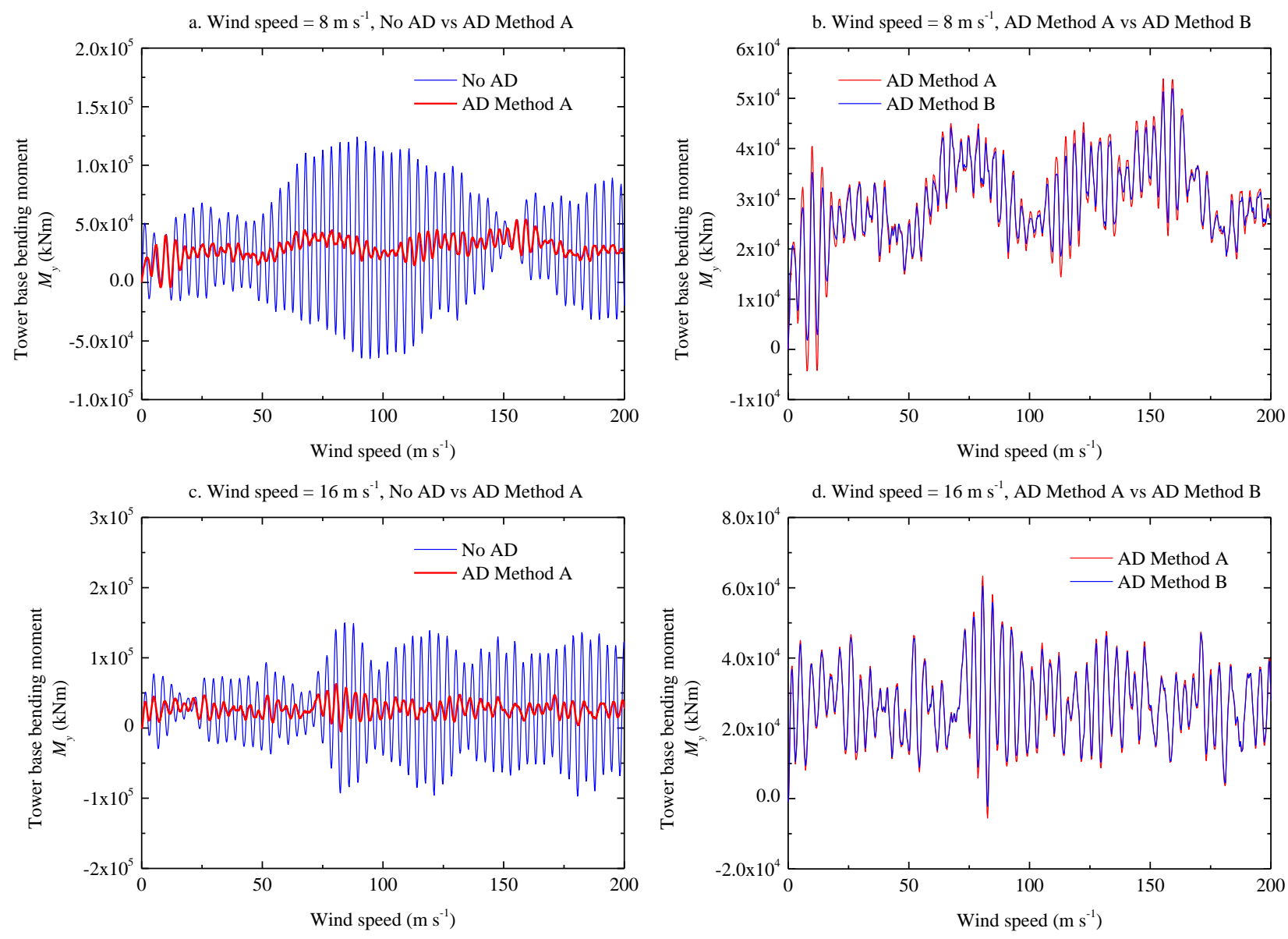

Fig. 11. Tower base bending moment under different wind speeds

The reduction in vibrations of the tower due to the aerodynamic damping will lead to an alleviation of the load. Fig. 11 shows the tower base bending moment $M_{y}$ predicted for two turbulent winds with mean wind speeds of $8 \mathrm{~m} \mathrm{~s}^{-1}$ and $16 \mathrm{~m} \mathrm{~s}^{-1}$ respectively. Also, for a clearer comparison, only a $200 \mathrm{~s} \mathrm{time} \mathrm{duration} \mathrm{is} \mathrm{displayed,} \mathrm{although}$ the simulation duration is $600 \mathrm{~s}$. As in the case of tower top deflection, the amplitude of the tower base bending moment is also significantly reduced if aerodynamic damping is considered, for both the $8 \mathrm{~m} \mathrm{~s}^{-1}$ and $16 \mathrm{~m} \mathrm{~s}^{-1}$ wind speeds (Figs. 11a and 11c). Figs $11 \mathrm{~b}$ and 11d indicate that, when using Method B to estimate the aerodynamic damping, the predicted load amplitude is consistently smaller than that predicted by Method A. The reduction in load amplitude is more obvious for the $8 \mathrm{~m} \mathrm{~s}^{-1}$ turbulent wind. For the $16 \mathrm{~m} \mathrm{~s}^{-1}$ wind, the average reduction in load amplitude during the $600 \mathrm{~s}$ duration is about $9 \%$, while for the $8 \mathrm{~m} \mathrm{~s}^{-1}$ wind, it is about $20 \%$. In these two simulations, the time-average values of the modal aerodynamic damping ratio estimated by Method A are $3.2 \%$ and $3.1 \%$ for the $8 \mathrm{~m} \mathrm{~s}^{-1}$ and $16 \mathrm{~m} \mathrm{~s}^{-1}$ turbulent winds respectively, while the aerodynamic damping ratios estimated by Method B are 5.4\% and 3.5\% respectively for the $8 \mathrm{~m} \mathrm{~s}^{-1}$ and $16 \mathrm{~m} \mathrm{~s}^{-1}$ winds. For the $8 \mathrm{~m} \mathrm{~s}^{-1}$ wind speed, a much larger increase in the aerodynamic damping is estimated by Method B, resulting in more 
load alleviation.

In order to obtain a comprehensive understanding of the influence of the aerodynamic damping on the fatigue loading on the tower of an offshore HAWT and the effect of using different aerodynamic damping estimation methods, a load analysis of the $5 \mathrm{MW}$ wind turbine tower was performed. The wind turbine class for the $5 \mathrm{MW}$ machine was considered to be IEC IA [22], corresponding to a Weibull wind speed distribution [25] with an annual mean wind speed of $10 \mathrm{~m} \mathrm{~s}^{-1}$ and a shape parameter of 2 .

Table 2 Wave parameters and the probability density of wind in conjunction with waves (only showing four wind speeds)

\begin{tabular}{cccc}
\hline Wind speed $\left(\mathrm{m} \mathrm{s}^{-1}\right)$ & Significant wave height $H_{s}(\mathrm{~m})$ & Peak wave period $T_{p}(\mathrm{~s})$ & Probability density \\
\hline \multirow{2}{*}{6} & 0.54 & 4.55 & 0.06925 \\
& 0.70 & 4.80 & 0.04625 \\
0.95 & 5.10 & 0.02315 \\
\multirow{2}{*}{12} & 1.45 & 5.74 & 0.06942 \\
& 1.80 & 6.10 & 0.04630 \\
& 2.31 & 6.41 & 0.02314 \\
18 & 3.04 & 7.76 & 0.02120 \\
& 3.50 & 8.00 & 0.01413 \\
& 3.95 & 8.16 & 0.00707 \\
24 & 5.03 & 9.67 & 0.00221 \\
& 5.80 & 10.00 & 0.00147 \\
& 6.57 & 10.73 & 0.00074 \\
\hline
\end{tabular}

The load analysis was carried out assuming turbulent wind fields with 11 different mean wind speeds ranging from $4 \mathrm{~m} \mathrm{~s}^{-1}$ to $24 \mathrm{~m} \mathrm{~s}^{-1}$. Three random turbulent 'seeds' were used for each mean wind speed and each of the wind time series lasts $600 \mathrm{~s}$. The random sea state was described using the JONSWAP spectrum [22]. The combined wind wave distribution was determined using scatter diagrams of a specific offshore site obtained from long term statistics, including significant wave height, peak wave period and wind speed. For each turbulent wind, three sea states were used in the load calculation. Therefore, in total there were $99(11 \times 3 \times 3)$ load cases simulated. Table 2 shows the wave parameters for four wind speeds and the combined wind wave probability density, which were used in the time-domain simulations. For the fatigue load estimation, the total number of each load case to be counted throughout the 20 -year lifetime can be determined according to the probability density. 
Each load case was simulated using three conditions: 1) considering only the wind;2) considering only the waves; 3) considering both wind and waves. For every 'wind only' case, tower loads were estimated both with and without consideration of aerodynamic damping.

To enable meaningful comparison of the load results, the concept of 'Fatigue Damage-Equivalent Load' (FDEL) was used to equate the fatigue damage represented by rainflow cycle-counted data to that caused by a single load range repeating at a single frequency [22]. Based on Miner's rule [52, 53], the damage-equivalent load is given by:

$$
L_{e q}=\left[\sum_{i=1}^{N} \frac{\left(L_{a i}+m_{f}\left|L_{m i}\right|\right)^{m}}{N}\right]^{\frac{1}{m}}
$$

where $L_{a i}$ and $L_{m i}$ are the amplitude and mean value of the load cycle respectively; $m$ is the slope of the SN curve, $N$ the number of cycle repetitions in the turbine lifetime, and $m_{f}$ the mean load sensitivity factor $\left(m_{f}=\right.$ $0.00035 \sigma_{u}-0.1$, where $\sigma_{u}$ is the ultimate stress for the material) [52].

The slope of the SN curve was assumed as $m=4$, which is within the range between 3 and 5 , typically chosen for steel tubular tower structure [22]. The damage-equivalent loads were then estimated for each load component assuming $1.37 \times 10^{8}$ cycles in the turbine lifetime of 20 years. Table 3 shows the obtained FDEL of tower base bending moment $M_{y}$, which is crucial in the fatigue design of the tower.

Table 3 FDEL of tower base bending moment $M_{y}$

\begin{tabular}{|c|c|c|c|c|c|c|c|}
\hline & \multicolumn{3}{|c|}{ Wind and wave } & \multicolumn{3}{|c|}{ Wind only } & \multirow{2}{*}{ Wave only } \\
\hline & No AD & AD Method A & AD Method B & No $A D$ & AD Method A & AD Method B & \\
\hline $\begin{array}{c}\text { FDEL of } \boldsymbol{M}_{\boldsymbol{y}} \\
(\mathrm{kNm})\end{array}$ & 118647 & 20173 & 18249 & 71030 & 14374 & 13124 & 58330 \\
\hline
\end{tabular}

It is clear that aerodynamic damping greatly affects the FDEL of $M_{y}$. The value of the FDEL of $M_{y}$ calculated without considering aerodynamic damping is more than 5 times that considering aerodynamic damping, in both the 'wind and wave' and 'wind only' cases. The actual fatigue load of the offshore tower ('wind and wave' case considering aerodynamic damping) is significantly less than the cumulative fatigue load (sum of 'wind only' and 'wave only' loads). Moreover, it is less than the fatigue load estimated considering only the waves, which means 
that the introduction of wind does not increase but reduces the fatigue load significantly. This is mainly due to the aerodynamic damping analysed above, which restrains the tower vibrations induced by hydrodynamic forces as the wind and waves are co-directional.

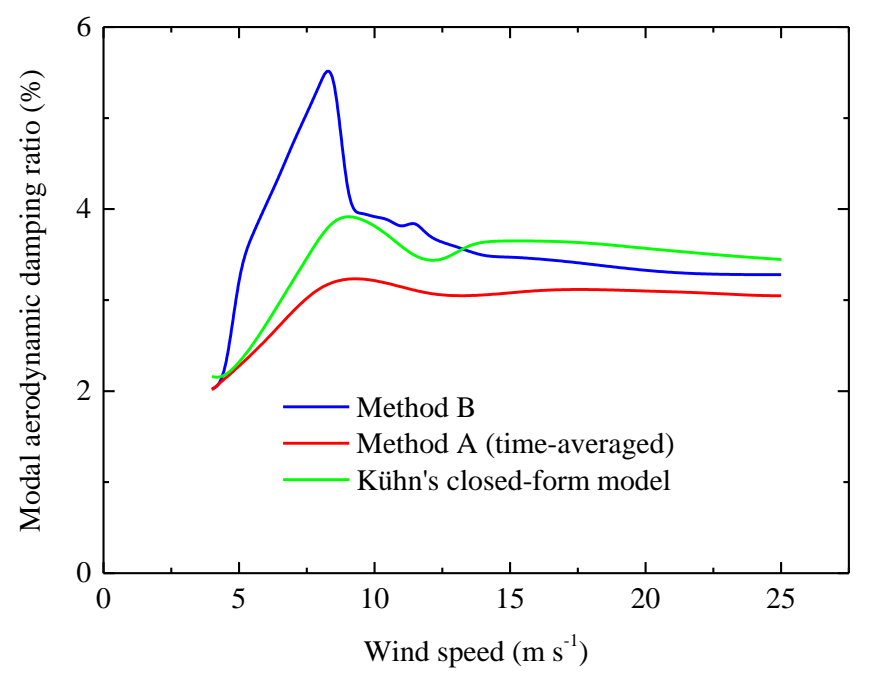

Fig. 12. Aerodynamic damping as a function of wind speed: Method A vs Method B

Table 3 also indicates that using Method B for estimation of aerodynamic damping will underestimate the fatigue load by about $9 \%$ in both the 'wind and wave' and 'wind only' cases, compared to Method A. This is due to the higher aerodynamic damping estimated by Method B, compared to that predicted by Method A. Fig. 12 shows the time-averaged value of the aerodynamic damping predicted by Method A for the above load analysis in the whole range of operating wind speed, in comparison with that predicted by Method B. It is found that the aerodynamic damping predicted by Method A is consistently lower than that predicted by Method B.

Fig. 12 also shows the aerodynamic damping predicted by Kühn's closed-form model [11]. The theory of Kühn's closed-form model is similar to that used in Method A, but without the consideration of correction for variablespeed wind turbine. It should also be noted that the results obtained by Kühn's closed-form model in Fig. 12 is based on the assumption of steady aerodynamics. It is found that, for the $5 \mathrm{MW}$ wind turbine, like Method B, Kühn's closed-form model also predicted consistently higher aerodynamic damping than that predicted by Method A. Compared to Method B, Kühn's closed-form model predicted lower aerodynamic damping below the rated wind speed, but higher aerodynamic damping above the rated wind speed.

The fatigue load results show that the consideration of aerodynamic damping in the tower load analysis is 
important. If this is not included in the analysis, it will lead to over-conservative design, resulting in significant increase in cost. The aerodynamic damping of an HAWT tower is mainly dominated by the rotor aerodynamics and the structure of the tower. The rotor aerodynamics under a turbulent wind field is complicated and is determined by the aerodynamic shape of the blade in conjunction with the aerodynamic characteristics of the airfoils applied. For different wind turbines, the aerodynamic damping may vary from turbine to turbine due to the difference in design. Fig. 13 shows the modal aerodynamic damping ratio predicted for a $2 \mathrm{MW}$ wind turbine under a $12 \mathrm{~m} \mathrm{~s}^{-1}$ turbulent wind, in comparison with that obtained for the $5 \mathrm{MW}$ wind turbine. In addition to the fluctuation under turbulent wind, the average value of the aerodynamic damping for these two turbines also shows considerable difference. This shows that using a constant value of aerodynamic damping for all designs is not appropriate.

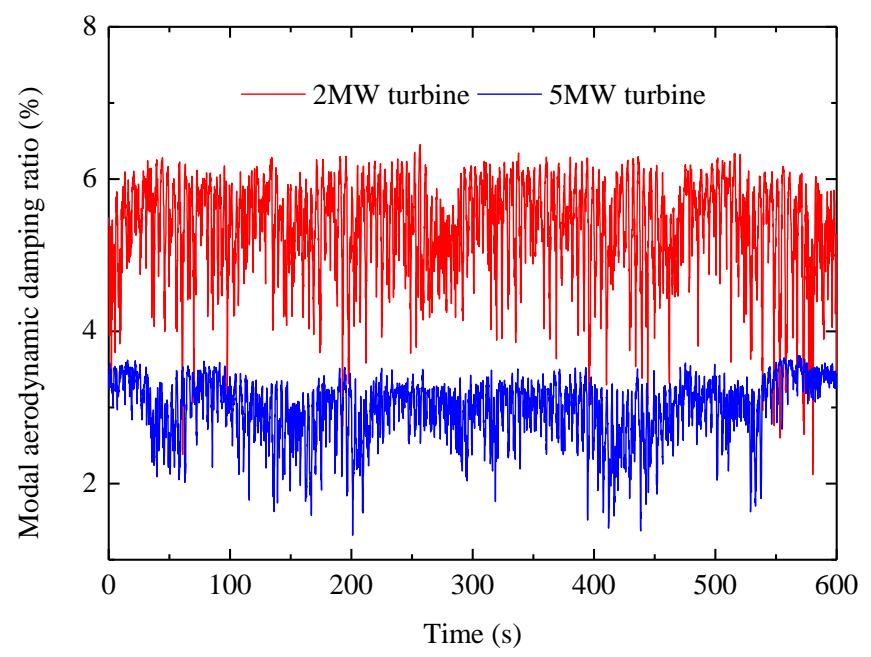

Fig. 13. Modal aerodynamic damping ratio of the tower for $2 \mathrm{MW}$ and $5 \mathrm{MW}$ wind turbines under $12 \mathrm{~m} \mathrm{~s}^{-1}$ turbulent wind, obtained using Method A.

Different aerodynamic damping prediction methods may lead to considerable deviation in the fatigue load estimates. Therefore, in the design stage, the aerodynamic damping calculation method should be carefully chosen to ensure an optimum and safe design. For the HAWT studied in this paper, Method B predicted higher aerodynamic damping than Method A. But this may not apply to other HAWTs. Generally speaking, Method A can provide more precise estimates of the aerodynamic damping, as it takes the unsteady aerodynamics including dynamic stall and dynamic inflow into account during the transient simulation. The disadvantage of Method A is that it is computationally much more expensive than Method B, as Method B only requires the solution of the BEM theory under steady wind and need not calculate the aerodynamic damping at airfoil level. In the load 
analysis of the 5 MW HAWT studied in this paper, Method B can also be a good choice. Although it will lead to a slightly less conservative design than Method A, the computing time will be greatly saved. However, to ensure more confidence in the design, Method A is recommended.

\section{Conclusions}

In this study, a load analysis for the tubular tower of an offshore HAWT is presented, including the calculation of transient aerodynamic loads and wave loads, and the solution of structural dynamics. Aerodynamic damping models are introduced and incorporated into the transient load analysis to account for the damping induced by the rotor aerodynamics. Based on this, the influence of aerodynamic damping on the tower load analysis of offshore HAWTs was investigated. The salient points can be summarised as follows:

(1) Wind turbines operate in a highly unstable environment. The associated unsteady aerodynamics will affect the aerodynamic damping as well as the loads on the turbine. Inclusion of the effects of dynamic inflow and dynamic stall in the aerodynamic model can not only reflect the transient aerodynamic loads caused by wind turbulence, yawing, rotational speed regulation and pitch regulation, but also improve the accuracy in the prediction of the transient aerodynamic damping using Method A.

(2) Different aerodynamic damping models present considerable deviation in the prediction results. In this study, Method A takes into account the transient aerodynamics and can predict the transient aerodynamic damping. It is more time-consuming, but provides more precise and conservative predictions.

(3) Load analysis of a 5MW offshore HAWT indicates that aerodynamic damping can greatly affect the structural response of an offshore HAWT in operation and plays a key role in restraining vibrations of the tower, and consequently significantly affects the lifetime fatigue loads on the tower. Therefore, in the wind turbine design stage, the aerodynamic damping should be taken into account to achieve an optimum design.

(4) As the directions of wind and sea waves are usually parallel, aerodynamic damping induced by the rotor aerodynamics can significantly reduce tower vibrations caused by hydrodynamic forces, reflecting that 
the fatigue load on the tower is much higher if only the effect of the waves is considered, compared to a consideration of the joint action of wind and sea waves.

(5) Aerodynamic damping for different wind turbines may vary due to difference in design. Therefore, applying a universal constant for aerodynamic damping to all designs is not recommended. The results obtained in this study suggest that calculation of aerodynamic damping under different wind speeds for a specific design is required.

(6) Results obtained by the two aerodynamic damping models show that different aerodynamic damping prediction methods may produce considerable difference in the prediction of the lifetime fatigue load of the tower. Therefore, in order to ensure a safe and optimum design, the method for calculating the aerodynamic damping should also be carefully chosen. Based on the results of the 5MW HAWT in this study, Method A is recommended to evaluate the aerodynamic damping as it is not only more precise but also produces more conservative estimates.

\section{Acknowledgement}

This study is supported by the National Natural Science Foundation of China (Grant No. 51276106). The authors are grateful for the financial support.

\section{Reference:}

[1] Salzmann DJC, van der Tempel J. Aerodynamic damping in the design of support structures for offshore wind turbines. European Offshore Wind Conference. Copenhagen, Denmark2005.

[2] Bonou A, Laurent A, Olsen SI. Life cycle assessment of onshore and offshore wind energy-from theory to application. Applied Energy. 2016;180:327-37.

[3] Shu ZR, Li QS, Chan PW. Investigation of offshore wind energy potential in Hong Kong based on Weibull distribution function. Applied Energy. 2015;156:362-73. 
[4] Danao LA, Edwards J, Eboibi O, Howell R. A numerical investigation into the influence of unsteady wind on the performance and aerodynamics of a vertical axis wind turbine. Applied Energy. 2014;116:11124.

[5] Melício R, Mendes VMF, Catalão JPS. Transient analysis of variable-speed wind turbines at wind speed disturbances and a pitch control malfunction. Applied Energy. 2011;88:1322-30.

[6] Rolland S, Newton W, Williams AJ, Croft TN, Gethin DT, Cross M. Simulations technique for the design of a vertical axis wind turbine device with experimental validation. Applied Energy. 2013;111:1195203.

[7] Sun H, Luo X, Wang J. Feasibility study of a hybrid wind turbine system - Integration with compressed air energy storage. Applied Energy. 2015;137:617-28.

[8] Global Wind Energy Council (GWEC). Global wind report: annual market update 2015. Brussels: GWEC; 2016.

[9] Carswell W, Johansson J, Løvholt F, Arwade SR, Madshus C, DeGroot DJ, et al. Foundation damping and the dynamics of offshore wind turbine monopiles. Renewable Energy. 2015;80:724-36.

[10] Esteban M, Leary D. Current developments and future prospects of offshore wind and ocean energy. Applied Energy. 2012;90:128-36.

[11] Kühn M. Dynamics and design optimisation of offshore wind energy conversion systems. Delft 2001.

[12] Wang L, Liu X, Kolios A. State of the art in the aeroelasticity of wind turbine blades: Aeroelastic modelling. Renewable and Sustainable Energy Reviews. 2016;64:195-210.

[13] Hansen MOL, Sørensen JN, Voutsinas S, Sørensen N, Madsen HA. State of the art in wind turbine aerodynamics and aeroelasticity. Progress in Aerospace Sciences. 2006;42:285-330.

[14] Liu X, Lu C, Liang S, Godbole A, Chen Y. Vibration-induced aerodynamic loads on large horizontal axis wind turbine blades. Applied Energy. 2017;185, Part 2:1109-19. 
[15] Shirzadeh R, Devriendt C, Bidakhvidi MA, P. G. Experimental and computational damping estimation of an offshore wind turbine on a monopile foundation. Journal of Wind Engineering \& Industrial Aerodynamics. 2013;120:96-106.

[16] Devriend C, Jordaens PJ, Sitter GD, Guillaume P. Damping estimation of an offshore wind turbine on a monopile foundation. EWEA 2012. Copenhagen, Denmark2012.

[17] Petersen JT, Madsen HA, Björck A, Ganander H, Winkelaar D, Brand A, et al. Prediction of dynamic loads and induced vibrations in stall. Copenhagen: Risø National Laboratory; 1998.

[18] Rasmussen F, Petersen JT, Madsen HA. Dynamic Stall and Aerodynamic Damping. Journal of Solar Energy Engineering. 1999;121:150-5.

[19] Valamanesh V, Myers AT. Aerodynamic damping and seismic response of horizontal axis wind turbine towers. Journal of Structural Engineering. 2014;140:04014090-1-8.

[20] Cheng Z, Madsen HA, Gao Z, Moan T. Numerical study on aerodynamic damping of floating vertical axis wind turbines. Journal of Physics: Conference Series. 2016;753:102001.

[21] Liu X, Zhang X, Li G, Chen Y, Ye Z. Dynamic response analysis of the rotating blade of horizontal axis wind turbine. Wind Engineering. 2010;34:543-60.

[22] Germanischer Lloyd (GL). Guideline for the certification of offshore wind turbines. Hamburg: Germanischer Lloyd WindEnergie GmbH; 2005.

[23] International Electrotechnical Commission (IEC). IEC 61400-3 Ed.1: Wind turbines -Part 3: Design requirements for offshore wind turbines. Geneva, Switzerland: International Electrotechnical Commission; 2007.

[24] AWEA and ASCE. Recommended practice for compliance of large land-based wind turbine support structures. Reston, VA: AWEA and ASCE; 2011.

[25] Burton T, Sharpe D, Jenkins N, Bossanyi E. Wind energy handbook. New York: Wiley; 2001. 
[26] Pitt DM, Peters DA. Theoretical prediction of dynamic inflow derivatives. Vertica. 1981;5:21-34.

[27] Gaonkar GH, Sastry VVSS, Reddy TSR, Nagabhushanam J, Peters DA. The use of actuator-disc dynamic inflow for helicopter flap-lag stability. Journal of the American Helicopter Society. 1983;28:79-88.

[28] Peters DA, He CJ. Correlation of measured induced velocities with a finite-state wake model. Journal of the American Helicopter Society. 1991;36:59-70.

[29] Suzuki A. Application of dynamic inflow theory to wind turbine rotors. Salt Lake City University of Utah; 2000.

[30] Gharali K, Johnson DA. Numerical modeling of an S809 airfoil under dynamic stall, erosion and high reduced frequencies. Applied Energy. 2012;93:45-52.

[31] Gharali K, Johnson DA. Dynamic stall simulation of a pitching airfoil under unsteady freestream velocity. J Fluids Struct. 2013;42:228-44.

[32] Wang S, Ingham DB, Ma L, Pourkashanian M, Tao Z. Numerical investigations on dynamic stall of low Reynolds number flow around oscillating airfoils. Computers \& Fluids. 2010;39:1529-41.

[33] Tarzanin FJ. Prediction of control loads due to blade stall. Journal of American Helicopter Society. 1972;17:33-46.

[34] Tran CT, Petot D. Semi-empirical model for the dynamic stall of airfoils in view of the application to the calculation of response of a helicopter blade in forward flight. Vertica. 1981;5:35-53.

[35] Øye S. Dynamic stall simulated as time lag of separation. Denmark: Technical University of Denmark; 1991.

[36] Gupta S, Leishman JG. Dynamic stall modelling of the S809 aerofoil and comparison with experiments. Wind Energy. 2006;9:521-47. 
[37] Leishman JG, Beddoes TS. A semi-empirical model for dynamic stall. Journal of American Helicopter Society. 1989;34:3-17.

[38] Hansen MH, Thomsen K, Fuglsang P, Knudsen T. Two methods for estimating aeroelastic damping of operational wind turbine modes from experiments. Wind Energy. 2006;9:179-91.

[39] Sinclair FM. Aerodynamic damping on offshore installations - a comparison of experimental measurements with theory. Journal of Wind Engineering and Industrial Aerodynamics. 1994;52:321-44.

[40] Damgaard M, Ibsen LB, Andersen LV, Andersen JKF. Cross-wind modal properties of offshore wind turbines identified by full scale testing. Journal of Wind Engineering and Industrial Aerodynamics. 2013;116:94-108.

[41] James GH, Carne TG, Veers PS. Damping Measurements Using Operational Data. Journal of Solar Energy Engineering. 1996;118:190-3.

[42] Garrad AD. Forces and dynamics of horizontal axis wind turbines. In: Freris LL, editor. Wind energy conversion systems. New York: Prentice-Hall; 1990. p. 119-42.

[43] Thomsen K, Petersen JT, Nim E, Øye S, Petersen B. A Method for Determination of Damping for Edgewise Blade Vibrations. Wind Energy. 2000;3:233-46.

[44] Clough RW, Penzien J. Dynamics of structures. New York: McGraw Hill; 1993.

[45] Spera DA. Wind turbine technology: Fundamental concepts of wind turbine engineering. 2nd edition ed. New York: ASME Press; 2009.

[46] Hansen MH, Gaunaa M, Madsen HA. A Beddoes-Leishman type dynamic stall model in state-space and indicial formulations. Copenhagen: Ris $\varnothing$ National Laboratory; 2004.

[47] Risø. Guidelines for design of wind turbines (2nd edition). Copenhagen: Risø National Laboratory; 2002. 
[48] Morison JR, O'Brien MP, Johnson JW, Schaf SA. The force exerted by surface waves on piles. AIME Petroleum Transactions. 1950 189:149-57.

[49] Goda Y. A review on statistical interpretation of wave data. Report of the Port and Harbour Research Institute. 1979;18:5-32.

[50] Riziotis VA, Voutsinas SG, Politis ES, Chaviaropoulos PK. Aeroelastic stability of wind turbines: the problem, the methods and the issues. Wind Energy. 2004;7:373-92.

[51] Hansen MH. Aeroelastic instability problems for wind turbines. Wind Energy. 2007;10:551-77.

[52] Lee YL, Pan J, Hathaway R, Barkley M. Fatigue testing and analysis - theory and practice. Burlington, MA: Elsevier; 2005.

[53] Miner MA. Cumulative damage in fatigue. Journal of Applied Mechanics. 1945;67:A159-A64. 